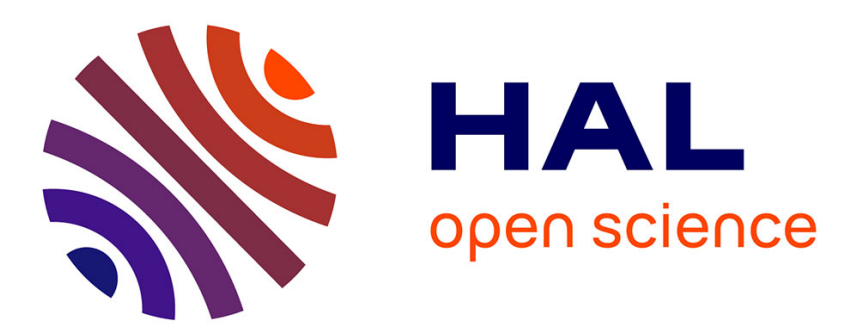

\title{
Semantic and functional diversification of reciprocal and middle prefixes in New Caledonian and other Austronesian languages
}

Isabelle Bril

\section{- To cite this version:}

Isabelle Bril. Semantic and functional diversification of reciprocal and middle prefixes in New Caledonian and other Austronesian languages. Linguistic Typology, 2005, 9 (1), pp.25-75. 10.1515/lity.2005.9.1.25 . halshs-00006059

\section{HAL Id: halshs-00006059 \\ https://shs.hal.science/halshs-00006059}

Submitted on 21 Dec 2006

HAL is a multi-disciplinary open access archive for the deposit and dissemination of scientific research documents, whether they are published or not. The documents may come from teaching and research institutions in France or abroad, or from public or private research centers.
L'archive ouverte pluridisciplinaire HAL, est destinée au dépôt et à la diffusion de documents scientifiques de niveau recherche, publiés ou non, émanant des établissements d'enseignement et de recherche français ou étrangers, des laboratoires publics ou privés. 


\title{
Semantic and functional diversification of reciprocal and middle prefixes in New Caledonian and other Austronesian languages
}

ISABELLE BRIL

\begin{abstract}
This article analyses the functions and meanings of the reflexes of the ProtoOceanic (POc) prefix *paRi- in New Caledonian languages and, based on comparisons with other Austronesian languages, seeks to account for their broad polyfunctionality and polysemy in New Caledonia. POc *paRi- originates from Proto-Austronesian and Proto-Malayo-Polynesian *paR-, as evidenced by their reflexes in various Formosan and Malayo-Polynesian languages. In Formosan languages, these prefixes are reciprocal markers and their combination with root reduplication marks plurality of reciprocal participants. In Malayo-Polynesian languages, the prefixes have a greater variety of functions and meanings: they are basically intransitive actor focus morphemes which also express middle voice and reciprocity as well as plural relationship, intensive, and frequentative meanings. In Oceanic languages, the reflexes of $P O c$ *paRi- express symmetrical, plural relationship and lower transitivity. POc *paRi- could also combine with two suffixes (POc*-i, *-aki) or with reduplication to express some other meanings (intensive, iterative, distributive, dispersive), as attested in various Oceanic languages. Thus, originally reciprocal prefixes in Formosan languages evolved into more polysemous morphemes in Malayo-Polynesian languages and developed in more or less conservative or innovative ways in Oceanic languages. In the northern New Caledonian languages, the decay of some of their combined suffixes and of reduplication probably triggered the conflation of these various functions and meanings into the preserved and productive prefixes.
\end{abstract}

Keywords: aspect, Austronesian, collective, cooperative, iterative, middle, New Caledonia, Oceanic, pluractionality, polysemy, reciprocal, reduplication, reflexive, semantic change, transitivity, voice 


\section{Polysemy of the reflexes of Proto-Oceanic *paRi-... (-i/-aki)}

This paper analyses the distribution, functions, and meanings of the reflexes of the Proto-Oceanic prefix *paRi- in New Caledonian languages with comparative data from other Austronesian languages. Section 1 delineates the polysemy of the ancestor forms and of their reflexes in various Austronesian languages. Section 2 presents the data from New Caledonian languages in comparison with other Oceanic languages. Section 3 draws on comparative data from diverse Austronesian languages belonging to various subgroups to analyse the semantic diversification of these Middle prefixes in northern New Caledonian languages and to suggest some paths of evolution. Finally, Section 4 assesses the data within a broader typological perspective.

The twenty-eight Kanak languages of New Caledonia belong to the Eastern Oceanic subgroup of the Austronesian family. New Caledonia comprises the Mainland (Grande Terre), the Loyalty Islands and various neighbouring islands (among which Belep in the far north and Ile des Pins in the south). See Map 1 for New Caledonia, and Appendix 1 for the subgrouping of the Austronesian languages considered.

\subsection{Oceanic languages}

New Caledonian languages have retained reflexes (see Appendix 2) of the polysemous Proto-Oceanic (POc) prefix * paRi-, itself a reflex of Proto-Austronesian (PAn) and Proto-Malayo-Polynesian (PMP) *paR- (Pawley \& Reid 1979: 110; see Section 1.2 below).

POc *paRi- was reconstructed by Pawley (1973: 150-151) as a collective/ associative, reciprocal, and iterative marker, referring not only to (i) "mutual interaction between the entities denoted by the subject of the verb", but also to (ii) "unified or conjoined action by a plural subject, or repeated action by a singular subject, or unification of objects". Pawley (1973: 152) pointed out that the label "reciprocal" was misleading and that "the strict reciprocal meaning was restricted to a subclass of verbs whose properties remain to be defined". In his analysis of Fijian, Dixon (1988: 178) also warns that "to label [the prefix] vei- as reciprocal tends to obscure its other functions" and that reciprocal is just a specification of the collective meaning; Churchward (1941) voiced a similar opinion. More recently, Lichtenberk (2000: 58) suggested that POc *paRibasically expressed plurality of relationship (subsuming reciprocal, collective, and chained actions), and states that there is no evidence that the reciprocal function was historically primary (2000: 32). Yet, he acknowledges that the notion of plurality of relations does not account for the middle functions of these prefixes and, consequently, he poses the notion of a "low degree of elaboration of situation" (2000: 55) as a second factor to account for a number of their other attested functions (reciprocal, depatientive, and kinship terms). 


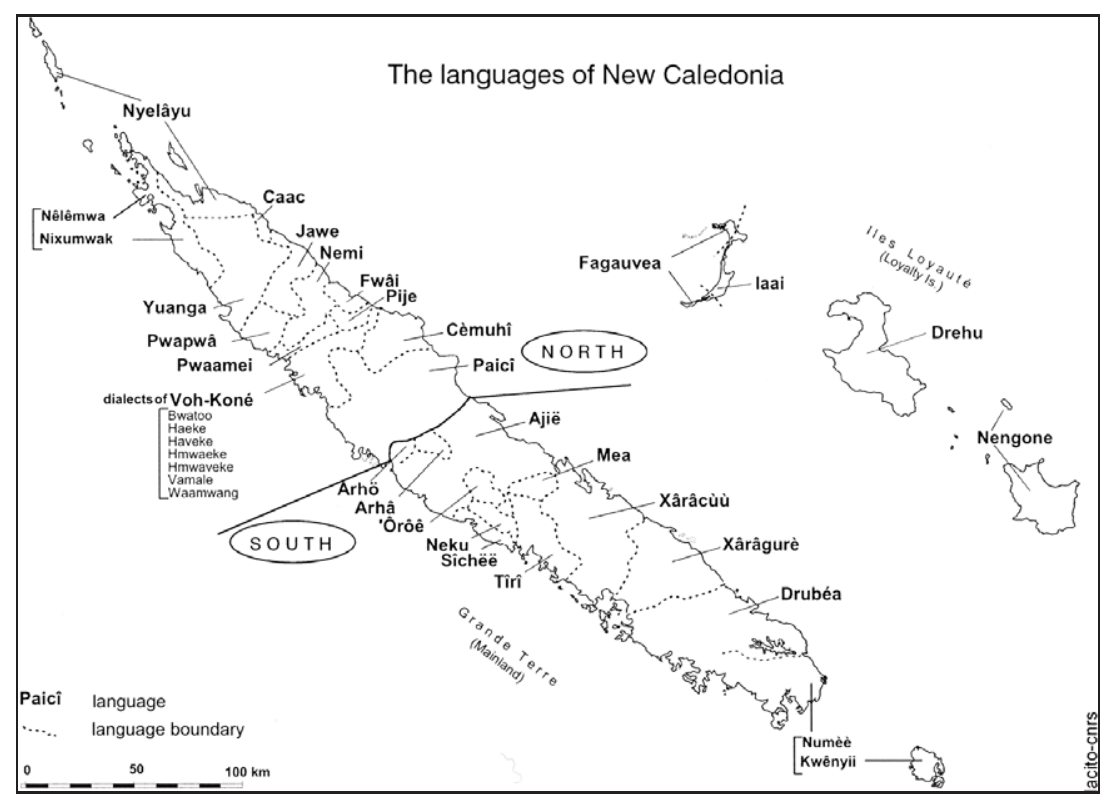

Map 1. New Caledonia

He thus concludes that these constructions were polysemous in Proto-Oceanic (2000: 55). While this may be true for Proto-Oceanic, it is not the case for Proto-Austronesian as evidenced by Formosan languages in which the prefixes are only reciprocal morphemes (Section 1.2).

Besides, there is evidence that POc *paRi-could combine with one of two suffixes $*_{-} i$ and $*_{-} a k i$; ${ }^{*} p a R i-\ldots$ - $i$ expressed reciprocal, iterative, and collective meanings, "combined or repeated action by a plurality of actors or affecting a plurality of entities" (Pawley 1973: 152), while *paRi-... -aki was used for distributive, dispersive actions (Lichtenberk 2000: 55-56). Various Oceanic languages also combine the prefixes with root reduplication (see Sections 2.7 and 3.2) to express iterative, intensive, distributive actions, states, and properties (as in Mekeo) and with intransitivizing functions. Table 1 (based on data detailed in Sections 2 and 3.2) lists the possible morphological combinations and their attested functions and meanings in Oceanic languages. Individual languages make specific selections of these combinations and of their functions and meanings: thus, in New Caledonian languages, there is no trace of the suffix $*_{-} a k i$, a marginal trace of $*-i$, and virtually no use of reduplication; such loss is the reason advanced to explain the great polysemy of the very productive reflexes of *paRi- in the northern languages, which are hypothesized to 
Table 1. Functions and meanings of the reflexes of $* \mathrm{pa}(\mathrm{R}) \mathrm{i}-\ldots-*_{\mathrm{i}} / *$-aki and combined reduplication in various Oceanic languages; $(+)$ indicates an infrequent combination

\begin{tabular}{|c|c|c|c|c|}
\hline & *paRi- & ${ }^{*} p a R i-\ldots-i$ & *paRi-...-aki & $\begin{array}{l}* \text { *aRi- + root } \\
\text { reduplication }\end{array}$ \\
\hline $\begin{array}{l}\text { Collective or associated actors, } \\
\text { multiple participants to an action }\end{array}$ & + & + & & \\
\hline $\begin{array}{l}\text { Collective/plural entities, mode of } \\
\text { grouping, augmentative meaning }\end{array}$ & + & & & + \\
\hline Reciprocal subjects/actors & + & + & $(+)$ & \\
\hline $\begin{array}{l}\text { Reciprocal or associated } \\
\text { objects/patients }\end{array}$ & + & & & \\
\hline No endpoint & & & & \\
\hline - Distributive, dispersive actions & & & + & + \\
\hline $\begin{array}{l}\text { - Intransitivizing (depatientive) } \\
\text { function }\end{array}$ & + & + & & + \\
\hline $\begin{array}{l}\text { - Multiple, iterative, intensive } \\
\text { actions }\end{array}$ & + & + & & + \\
\hline $\begin{array}{l}\text { Reference to states and properties } \\
\text { (often derived from frequentative } \\
\text { or habitual actions) }\end{array}$ & + & & & + \\
\hline $\begin{array}{l}\text { Comparison (symmetrical } \\
\text { property) }\end{array}$ & + & & & \\
\hline
\end{tabular}

have conflated all these functions and meanings (as appears in the first column of Tables 1 and 2).

The productivity and polysemy of these prefixes is highly variable in Oceanic languages, as is their combination with suffixes or with reduplication (Sections 2, particularly 2.7, and 3.2).

Such combined morphemes are attested in various Oceanic languages: BI... -ai in Mekeo has distributive, dispersive meanings (Jones 1998: 374-380); $e-\ldots-i$ in Manam (Lichtenberk 1983: 211-214), kwai-...-i in Toqabaqita (Lichtenberk 1991: 172), fe-...-i in Samoan (Milner 1966) express reciprocity; in Fijian, vei-...-i refers to reciprocal actions, while vei-...-yak(i) marks dispersive actions, done in all directions, around, here and there, up and down, back and forth (Milner 1972: 111-113); in Tongan, fe-...-i marks collective or simultaneous actions, while $f e-\ldots$-aki expresses reciprocal or dispersive actions (Churchward 1953: 257). In New Caledonia, there is no trace of the suffix 
$*_{-}$aki and only Nêlêmwa has a reflex of *-i (Bril 2002), pe-...-i expresses reciprocity (see Section 2.4.2 and Table 4). In the languages of the Loyalty Islands (New Caledonia), the collective and the extended reciprocal meanings (involving plural participants) are expressed by combined suffixes or morphemes which are not reflexes of $*_{-} i$ and $*_{-} a k i$, but which follow the same pattern, as in Drehu $i-\ldots-n y$ or $i-. . . k e u$ (keu 'together'). Indeed, all the Loyalty Islands languages make use of a more or less grammaticalized morpheme meaning 'together' (Section 2.2.1) to express the extended reciprocal and collective meanings.

\subsection{Non-Oceanic Austronesian languages}

Let us now turn to the functions and meanings of these prefixes outside the Oceanic group, in languages belonging to various other higher groups of the Austronesian family (see Appendix 1). Based on ongoing research on data from several first-order groups of Formosan languages (Rukai, Pazeh, Paiwan, Saisiyat, Puyuma), Zeitoun (2002) suggests the following Proto-Austronesian (PAn) reconstructions for these prefixes, which appear to be reciprocal markers whose form varies according to whether the verb is active or non-active ${ }^{1}$ and finite or non-finite: PAn *maR- $\sim$ *paR- appear with non-active verbs, while PAn *ma-Ca- $\sim{ }^{*} p a-C a-$, involving Ca-reduplication, ${ }^{2}$ appear with active verbs; *ma- forms associate with finite verb forms while *pa-forms associate with non-finite verb forms. The prefix *maR-together with kinship nouns also expresses reciprocal kinship (Section 3.1.1). When combined with root reduplication, these prefixes refer to a plurality of participants in reciprocal relation. Root reduplication expresses cooperative action involving plural participants ('do together') and frequentative meaning ('do often').

Within the Malayo-Polynesian branch, two prefixes are also reconstructed in Proto-Malayo-Polynesian (PMP) or Proto-Extra-Formosan ${ }^{3}$ (PEF, Reid 2004), *paR- (for non-finite, atemporal predicates) and *maR- (for finite, non-past predicates), *maR- resulting from the fusion of the actor focus affix $*\langle\mathrm{UM}\rangle$

1. Non-active verbs, which Zeitoun labels "stative verbs", are verbs such as 'love, hate, know, believe, be good/bad, be happy', etc.

2. In Ca-reduplication, the first consonant is copied and prefixed to the base with a default vowel (often /a/) insertion.

3. In this article, the traditional term Proto-Malayo-Polynesian will be used rather than the more specific label Proto-Extra-Formosan advocated by Reid (2004). Proto-Extra-Formosan refers to the parent language of all Austronesian languages spoken outside Formosa. It is roughly equivalent to what is traditionally referred to as Proto-Malayo-Polynesian, which Reid considers a misnomer in terms of its implications (that its Western languages are Malayic) since the northern languages of the Philippines constitute a separate branch of the family, all the languages south of this area constituting a subgroup which is more appropriately labeled Malayo-Polynesian (Reid personal communication). 
+ *paR-: *paR- appears with dependent, imperative verb forms, nouns, and adjectives and *maR- with independent, neutral, indicative verb forms. These more polysemous prefixes are basically intransitive actor focus morphemes which also express middle voice (Adelaar 1984, Ross forthcoming), among which the reciprocal and reflexive meanings as well as durative actions. Blust (forthcoming) also reconstructs a prefix *paRi- in Proto-Eastern Malayo-Polynesian as a reciprocal and collective marker.

In Tagalog, the polysemous prefix mag-, ${ }^{5}$ a reflex of Proto-Extra-Formosan *maR-, resulting from the fusion of * $\langle\mathrm{UM}\rangle$ and $* p a R$ - (Reid \& Liao 2004), marks reciprocals (b-um-ati 'greet someone' > mag-bati 'greet each other', $h$ um-iwalay 'separate something' > mag-hiwalay 'separate from one another', Schachter \& Otanes 1972: 293), self-directed actions (um-ahit 'shave someone' > mag-ahit 'shave oneself', Pittman 1966: 12-13, 18-19, cited in Reid \& Liao 2004: 49-50), plural and repeated actions ( $p$-um-utol 'cut' > mag-putol 'cut several things', Himmelmann forthcoming a: 20), it also expresses exertion, intensive, durative, and frequentative meanings ( $k$ ain $>k$-um-ain 'eat' $>$ mag-kain 'eat often'). It is an Actor voice prefix which also acts as an intransitivizing and stativizing marker denoting a state or profession. Though magis more polysemous than the Formosan reciprocal prefixes, its functions and meanings can be assigned to two basic notions: (i) reciprocal, symmetrical, and plural relationship, (ii) lower transitivity as an intransitive actor and middle voice marker.

For ease of reference, these prefixes will be referred to as M-prefixes, a cover term for middle prefixes.

\subsection{Middle prefixes and reduplication in Austronesian languages}

Data from Malayo-Polynesian languages (Tagalog, Malay, Indonesian, see Section 3.1.2) and a number of Oceanic languages show that the M-prefixes often combine with reduplicated verb roots to express plural relationship, frequentative and intensive meanings. In Oceanic languages (Section 3.2.1), the prefixes often combine with root reduplication to denote iterativity, intensity, plural relationship, grouping, or distributive actions, as in Fijian (Milner 1972: 111-112) and Samoan (Milner 1966). All these meanings are expressed by the prefixes alone in northern New Caledonian languages. Thus, the innovation in

4. Proto-Malayo-Polynesian *maR- "is a surface representation of a deep structure *-um- + *paR-" (Wolff 1973: 74); see also Zorc 1977, Reid 1987, Reid \& Liao 2004, Zobel 2002: 408-409.

5. Prefixes display alternation of the initial consonant, as in pag-/mag-/nag-; the /p-/ form is the initial form (used as gerund or imperative), /m-/ marks non realis, and $/ \mathrm{n}-/$ realis. The $/ \mathrm{p}-/$ initial bases probably contain a fossilized prefix; mag- probably derives from * $p$-um-ag- and nag-from *p-in-ag- (Himmelmann 2004). 
New Caledonian languages is not so much in the wide range of meanings of these prefixes (summarized in Table 2 and analysed in Section 2), but in the fact that these prefixes conflate meanings and functions which are marked by combined affixes or by reduplication in other Austronesian languages (see Table 1, Sections 3.1 and 3.2.1), but not in New Caledonia (Section 3.2.3).

Lichtenberk (2000: 55-56) states that the middle meanings and functions of these prefixes are uncommon in Oceanic languages and that they essentially express plurality of relations. But the data from New Caledonian languages (Section 2) and various other Oceanic languages analysed in this paper (Section 2.7) show that their middle functions are not uncommon; besides, plurality of relations is inherent to reciprocal and symmetrical relations and might naturally stem from them. Comparison with other Austronesian languages also suggests that the reciprocal and middle functions were originally primary even though they diversified later.

\subsection{Middle voice defined}

Before proceeding, let us first attempt to delimit the notion of middle. Benveniste (1966) defines it as a situation in which "the verb indicates a process in which the subject is the locus [...] of the process. [... T] he subject acts by affecting itself". ${ }^{6}$ In slightly different terms, Kemmer (1993: 243) defines the middle as "a semantic area comprising events in which the Initiator is also an Endpoint or affected entity". It also encodes situations in which (i) either the agent/initiator or the patient/endpoint is lacking (Croft 1991) or (ii) the agent and patient roles are not clearly distinguishable (Kemmer 1993), since they are symmetrical as in reciprocal actions, or coreferential as in reflexive/selfdirected actions.

Crosslinguistically, the polysemy of middle markers is very common (Kemmer 1993, Frajzyngier 2000, Nedjalkov \& Guentchéva (eds.) forthcoming). Thus, the French "pronominal" construction expresses the reflexive or reciprocal meaning: ils se lavent 'they wash (themselves or each other)', and various other middle notions characterized by the fact that the subject is the locus of the action (il s'étonne 'he is astonished'), or that there is no initiator (la porte s'ouvre 'the door opens' or la maison s'écroule 'the house collapses'), or that the subject is the locus of a generic property or a state (ça se lave 'it washes').

Middle diathesis correlates with degrees of transitivity; as Kemmer (1993: 247) puts it:

the scale of transitivity forms the conceptual underpinning for voice systems in general and for reflexive and middle marking systems in particular. Thus transitiv-

\footnotetext{
6. "Le verbe indique un procès dont le sujet est le siège. [...] Le sujet est le lieu du procès. [...] Le sujet effectue en s'affectant" (Benveniste 1966: 172-173).
} 
ity is the broader phenomenon within the framework of which voice phenomena must be understood.

The middle constitutes an intermediate category on the scale between the prototypical one- or two-argument constructions and prototypical intransitive or transitive constructions.

The most frequent source of middle markers are reflexives (Kemmer 1993), but not in Austronesian languages since no reflexive morpheme is reconstructed either for Proto-Austronesian or Proto-Oceanic. In many Oceanic languages, reflexives/self-directed actions are expressed either by lexically reflexive intransitive verbs, or by transitive verbs with coreferential arguments, or by reflexes of *paRi-.

\section{Survey of the reflexes of POc *paRi- in New Caledonian languages}

The basic notions encoded by the reflexes of the Proto-Oceanic prefix *paRiin New Caledonian languages (Table 2) are threefold: (i) reciprocal and symmetrical relations, (ii) plural or collective actions or relations, and (iii) lower transitivity. Individual languages make different selections from those notions, which need not all co-occur. Here is a summary of the attested meanings and functions of these prefixes:

(i) reference to collective, associative actions (do together), chaining (action done in a chain), modes of grouping, augmentative meaning;

(ii) symmetrical agent and patient roles, as in reciprocal actions (do to each other) or non-distinct agent and patient roles as in self-directed actions (do to oneself);

(iii) absence of one of the two prototypical entities (agent or patient) of a transitive action, resulting either in the deagentive or depatientive intransitivizing function of the middle; as either (a) in agentless actions, lacking an initiator or controller, as in spontaneous, unintentional actions, or (b) in actions in which the subject is the locus/patient of the process, not its initiator (as in fall by itself, the door opens, it moves), or (c) in cases where the subject is the locus of a property or a state;

(iv) actions without an endpoint, such as tentative, aimless, or dispersive actions, or aspectually unbounded (non-completed, durative or iterative) actions, correlating with the notion of non-fully affected patients and consequently to a lower degree of transitivity and to intransitivization.

In order to hierarchize the properties from core to peripheral and to help visualize them, Table 2 organizes the functions and meanings of the prefixes (from top to bottom) according to their frequency in the various groups of New Caledonian languages. Among the core notions are the collective, the reciprocal meaning, and various other middle notions marking the lack of initiator or of endpoint or marking non-distinct initiator and endpoint as in self-directed 
Table 2. Functions and meanings of the reflexes of *pa(R)i- in New Caledonian languages (the shaded areas signal non-existent meanings or functions)

\begin{tabular}{|c|c|c|c|c|}
\hline & $\begin{array}{l}\text { Far North: } \\
\text { Nêlêmwa }\end{array}$ & $\begin{array}{l}\text { North: } \\
\text { Bwatoo, } \\
\text { Cemuhî }\end{array}$ & $\begin{array}{l}\text { South: } \\
\text { Ajië, } \\
\text { Xârâcùù }\end{array}$ & $\begin{array}{l}\text { Loyalty Islands: } \\
\text { Drehu, Iaai, } \\
\text { Nengone }\end{array}$ \\
\hline Collective or associated actors & + & + & + & $\stackrel{+}{+}$ \\
\hline Reciprocal subjects/actors & + & + & + & $\begin{array}{c}+ \\
(+ \text { adjunct, suffix })\end{array}$ \\
\hline Chaining & + & + & & Nengone \\
\hline $\begin{array}{l}\text { Reciprocal or associated objects / } \\
\text { patients }\end{array}$ & + & + & & Drehu \\
\hline $\begin{array}{l}\text { No initiator } \\
\text { - Spontaneous, unintentional, } \\
\text { solipsistic actions }\end{array}$ & + & + & & \\
\hline $\begin{array}{l}\text { No endpoint } \\
- \text { Tentative, non-directed, } \\
\text { dispersive actions }\end{array}$ & + & + & & \\
\hline $\begin{array}{l}\text { - Non-completed, durative actions } \\
\text { - Depatientive function } \\
\text { - Iterative, intensive actions }\end{array}$ & + & $\begin{array}{l}+ \\
+ \\
+\end{array}$ & $\begin{array}{l}\text { Ajië } \\
\text { Xârâcùù } \\
\text { Xârâcùù }\end{array}$ & $\begin{array}{l}\text { Iaai } \\
\text { Drehu, Iaai }\end{array}$ \\
\hline $\begin{array}{l}\text { Self-directed actions (non-distinct } \\
\text { initiator and endpoint) }\end{array}$ & & + & + & Drehu \\
\hline $\begin{array}{l}\text { Comparison (symmetrical } \\
\text { property) }\end{array}$ & + & + & & \\
\hline $\begin{array}{l}\text { Deverbal abstract nouns referring } \\
\text { to properties }\end{array}$ & & Cemuhî & Ajië & Drehu, Iaai \\
\hline $\begin{array}{l}\text { Collective nouns, augmentative } \\
\text { meaning }\end{array}$ & & & & Drehu \\
\hline
\end{tabular}

actions. Among the more peripheral functions of the prefixes are the comparative predicates, which indicate symmetrical properties (Section 2.6.3.3), the reference to deverbal abstract nouns or to collective nouns with augmentative meaning. 


\subsection{Productivity, polysemy, and polyfunctionality}

The reflexes of POc *paRi-...(-i) in New Caledonian languages ${ }^{7}$ (M-prefixes) display various degrees of productivity, polysemy, and polyfunctionality.

In most northern languages, the M-prefixes are very productive, polysemous, and polyfunctional (see Table 2), in contrast with the non-productive M-prefixes of the southern languages (Ajië, Xârâcùù; in Tîrî, spelled Tinrin in Osumi (1995), the prefix is decayed). In the Loyalty Islands, the situation is intermediate. In the languages with non-productive or decayed M-prefixes, reciprocal, self-directed/reflexive, and other middle meanings may be expressed by transitive verbs with coreferential arguments (Section 2.3.2).

As Table 2 shows, collective and reciprocal actions are common to all the languages, but the M-prefixes have various other meanings which indicate a lesser degree of transitivity or non-prototypical transitivity, sometimes including reflexives. The resulting semantic ambiguities are resolved by affixes or lexical adjuncts (Section 2.6.5). The comparative function refers to symmetrical properties and is specific to the northern and far northern languages (Bwatoo, Cemuhî, Nêlêmwa, see Section 2.6.3.3), its use is restricted to nominal and stative predicates.

In most New Caledonian languages, reflexivity is expressed either by intransitive verbs, by labile verbs used intransitively, or by transitive constructions with coreferential arguments (Iaai, Nengone, Tîrî, Xârâcùù, Nêlêmwa, Nyelâyu). In a few languages, Drehu (Loyalty Islands, Section 2.2.3.3), Ajië and Xârâcùù (south, Section 2.3.1), Bwatoo and Cemuhî (north, Section 2.4.1), the prefixes also express self-directed actions, but only with a few verbs of grooming or cognition. In Ajië and Xârâcùù where the prefix is unproductive, self-directed actions are expressed either by the prefix or by coreferential arguments (Section 2.3.2). And in Bwatoo (see (21), (26b)), self-directed actions are expressed by a combination of the prefix and coreferential arguments.

Given such variation, the analysis will proceed areally, with more attention on one far northern language, Nêlêmwa, where I collected fieldwork data. Section 3 will analyse comparative data from other Austronesian languages and make some hypotheses to account for the New Caledonian data.

\subsection{Loyalty Islands languages}

In the languages of the Loyalty Islands (Drehu, Iaai, and Nengone), the prefixes generally combine with suffixes or adjuncts to express collective and reciprocal actions.

7. In the Loyalty Islands, those reflexes have an extremely reduced phonetic form (see Appendix 2). 
When not combined with any other morpheme, the prefixes have other middle functions and meanings: they derive intransitive verbs whose subject is the locus of a state or property rather than an agent or initiator (Drehu, Iaai, Nengone), and they also mark deverbal abstract nouns (Drehu, Iaai); for similar properties in Malayo-Polynesian languages, see Section 1.2. In Drehu, they express a mode of grouping, have augmentative meaning, and refer to selfdirected actions with verbs of grooming.

2.2.1. Reciprocal and collective actions. In Drehu, Iaai, and Nengone, the collective and reciprocal meanings are generally expressed by combining the prefix and one additional morpheme, $k e u(n)$ (Drehu), ${ }^{8}$ köu (Iaai), jeu (Nengone) meaning 'together'.

In Drehu, the prefix $i$ - alone also refers to intrinsically reciprocal actions or to restricted reciprocity, i.e., involving two participants: $i$-aja 'desire/love each other, mutual love' (aja 'will/want'); $i$-atre 'know each other' (atre 'know'); $i$-loi 'make good, reconcile each other, reconciliation' (loi 'good'); $i$-nu 'separate, take leave' ( $n$ u 'leave'); $i$-saaze 'exchange' (saaze 'change'); $i$-sili 'join' (sili 'fasten, tie') (Moyse-Faurie 1983: 131-134; Sam 1995: 92).

The prefix $i$ - combined with keu 'together' refers to collective actions or to extended reciprocity, i.e., involving more than two participants: $i$-sue keu 'shout at each other/one another'; $i$-thoi keu 'lie to each other/one another' (thoi 'lie'); $i$-xou keu 'fear one another'(xou 'be afraid, fear'); i-penyi keu 'hustle each other/one another, hustling' (peny 'jostle, hustle', Lenormand no date).

The combined morphemes involving keu(n) (Drehu), köu (Iaai), and jeu (Nengone) also refer to collective or associated objects in symmetrical or reciprocal relation: i-cane keun 'sow together' (can 'sow'; Dubois no date); i-alethe keun 'hang/hook together' (alethe 'hang, hook'; Dubois no date); compare $i$ casi keun 'hold a meeting' and i-casine keun 'put together' (acasin 'make a heap, gather') (Lenormand no date).

The prefix $i$-is very productive in Drehu to judge from the long list of derived words (about 20 pages) in Sam's dictionary (1995).

In Nengone, the prefixes $e-\sim i$ - alone focus on the actor of a collective (see $1 \mathrm{a}, \mathrm{d}, \mathrm{e})$, reciprocal (1b), or chained action (1c) with little role differentiation.

8. In Drehu (Sam 1995: 166), another discontinuous morpheme $i$-...-ny refers to collective or associated subjects or derives deverbal nouns: $i$-hmuli-ny 'sleep together' ( $h m u l$ 'sleep'); $i$ cile-ny 'stand together, a group of standing people' (cil 'stand'); $i$-sue-ny 'shout together' (sue 'shout'); i-treije-ny(i) 'cry together' (treij(e) 'cry, be sad'); $i$-wangatrehmeku-ny 'be jealous (of each other), jealousy' ( $<$ wangatrehmekun 'be jealous of someone'). 


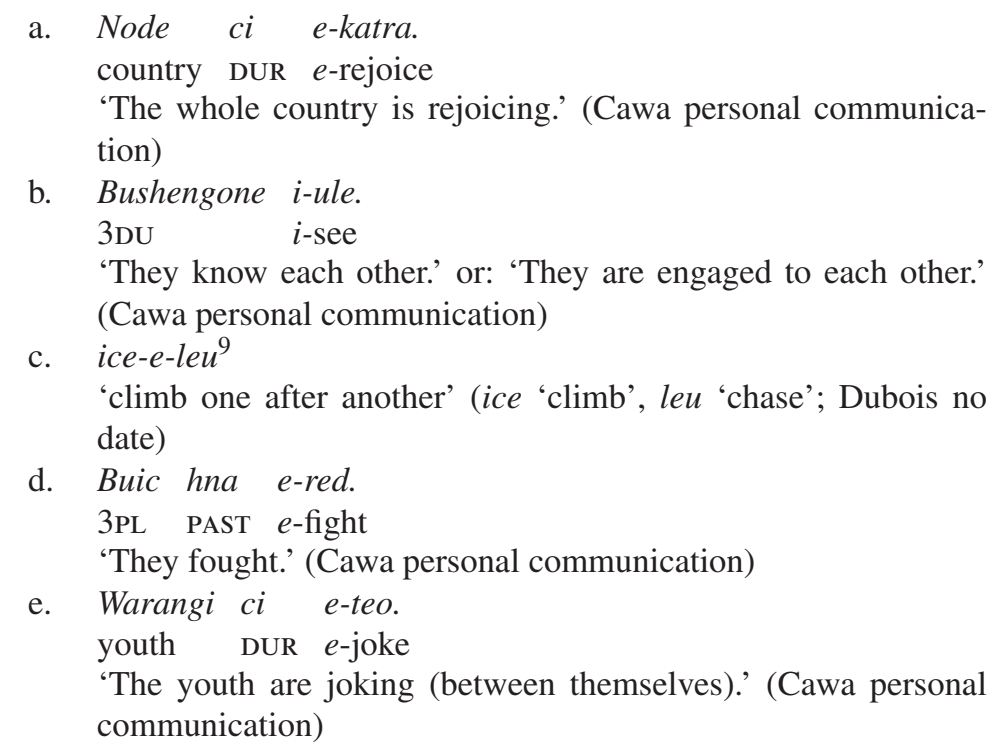

In contrast, the combination of $e$ - and jeu 'together' stresses the reciprocal meaning: buic hna e-red 'they fought' (1d) vs. buic hna e-rede jeu 'they fought against one another' (Cawa personal communication); warangi ci e-teo 'the youth are joking (between themselves)' (1e) vs. warangi ci e-teo jeu 'the youth are laughing at one another' (Dubois no date); e-leu 'chase together' vs. e-leu jeu 'chase one another' (Dubois no date); e-katra 'rejoice together' vs. e-katra jeu 'congratulate each other' (Dubois no date); see also e-katu jeu 'help each other', e-keco jeu 'hate one another' (Dubois no date).

In Iaai (Ozanne-Rivierre 1976: 176-178), the combined morphemes $i$ - (before labial consonants and round vowels) $\sim \ddot{u}$ - (elsewhere) ... köu express collective actors and restricted or extended reciprocity: $i$-oo köu 'meet together' (oo 'arrive'). They may also combine with coreferential arguments (see (2)) to disambiguate reciprocals from the collective meaning.

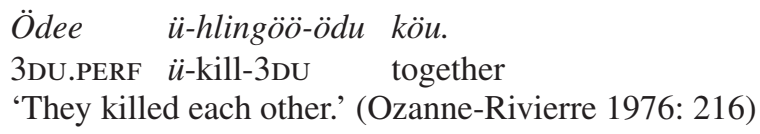

2.2.2. Symmetrical positions. In Drehu (3), Iaai (5), and Nengone (4), with nominal or stative predicates, the prefixes refer to symmetrical positions or postures. Again, Iaai (5) makes use of the heavy construction which combines the prefix with coreferential arguments.

9. Compare with the non-reciprocal expression ice-leu 'climb after someone, lit. climb chase'. 
(3) Drehu

i-qëmeke keu

'be facing each other' (qëmek 'face') ${ }^{10}$ (Sam 1995: 90)

(4) Nengone

a. Buic $\mathrm{ci}$ i-co jeu. ${ }^{11}$

3PL DUR $i$-back together

'They are sitting back to back.' or: 'They are hostile to each other.' (Dubois no date)

b. Bone ci e-tada jeu ne Pua.

3SG DUR $e$-front together COMIT Pua

'He's standing face to face with Pua.' (Dubois no date)

(5) Iaai

Ödru-mwe ü-hotuu-dru köu.

3DU.PRES $\ddot{u}$-back-3DU together

'They are back to back.' (Ozanne-Rivierre 1984)

2.2.3. Other functions and meanings of the M-prefix. These other functions also involve (i) either the notion of collective or plural relationship, or (ii) the deagentive or depatientive properties which are characteristic of the middle domain, or (iii) self-directed actions.

In Drehu, when $i$ - is prefixed to nouns, it has collective or augmentative meaning: $i$-bii 'swarm of bees' (bii 'bee'); $i$-nu 'coconut field' ( $n u$ 'coconut'); $i$-puaka 'big pig' (puaka 'pig'); $i$-laulau 'large table' (laulau 'table'); $i$-hnaine 'long hair' (hnaine 'hair'); $i$-jun(e) 'skeleton' (jun(e) 'bone'); i-munun(e) 'shoal of picot-fish' (munun(e) 'picot-fish') (Moyse-Faurie 1983: 131-132; Sam 1995: 84-88). But it may also have diminutive, attenuative meaning: $i$-ulili 'speak in a low voice, softly' (ulil(i) 'rumble, roar'; Sam 1995: 90).

The prefixes also derive intransitive or stative predicates referring either to a generic action or to a (resulting) property of the subject. Examples from Drehu include $i$-hej 'to bite (intr.)' (hej 'to bite' (tr.)); $i$-drei 'be obedient' (dreng 'obey' $>$ drei is the indeterminate transitive form); $i$-sili 'be attached' ( sil 'attach' > sili is the indeterminate transitive form) (Moyse-Faurie 1983: 132-133; Sam 1995: 90); for Iaai see (6) and for Nengone (7). These prefixes also ap-

10. This can be transitivized as: i-qëmeke keun(e) 'put facing each other'.

11. This expression is still accepted but disused (Cawa personal communication); icojeu now tends to be lexicalized and written as one word, with the meaning 'mutual, corresponding, adapted': icojeu kore uane bushengone [mutual the thought 3DU] 'they agree'. 
pear with deverbal abstract nominals: Drehu $i$-thel 'to search (intr.), a search' (thel 'to look for'); Iaai ü-hlingə 'crime, be a killer' (hlingə 'to kill'); $\ddot{u}$-asin 'nursing, be a nurse' (asen 'to nurse') (Ozanne-Rivierre 1976: 178).

(6) Iaai

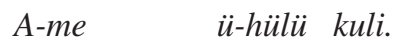

3sG(process) $\ddot{u}$-bite dog

'It is a dog that bites, i.e., it is a biting dog, this dog bites' (OzanneRivierre 1976: 176)

(7)

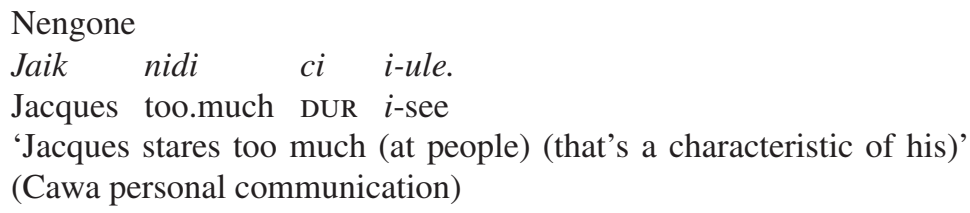

By definition, properties or states are unbounded and lack an endpoint; the subject is the locus of the property; these are typical middle notions.

Only in Drehu does the M-prefix refer to self-directed actions and then only with a few verbs of grooming: $i$-ciny 'shave (oneself)' (cin 'shave'); $i$ $s e j$ 'comb (oneself)' ( $s e j$ 'comb'). The verb is intransitivized and the action is actor-oriented.

In Iaai and Nengone, reflexivity is expressed either by intransitive verbs or by transitive verbs with coreferential arguments:

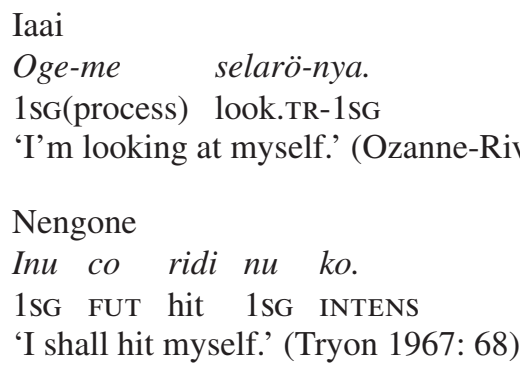

To conclude, in the languages of the Loyalty Islands, the M-prefixes have a broad range of middle functions: Actor oriented actions, depatientive/deagentive functions, reference to states and properties, reciprocal and collective meanings. The collective and extended reciprocal meanings are generally marked by the M-prefix combined with a morpheme meaning 'together' and in Iaai by the further addition of a coreferential object pronoun (see (2), (5)). Specific to Drehu is the reflexive meaning of the prefix, restricted to verbs of grooming. 


\subsection{Southern languages of the mainland of New Caledonia}

In the three southern languages of the mainland (Grande Terre) with available data, the M-prefix is either not productive (Ajië, Xârâcùù) or decayed as in Tîrî (Osumi 1995). But where attested, the M-prefixes express collective, reciprocal, and self-directed actions. The other functions seem to be language-specific.

2.3.1. Reciprocal, collective, and reflexive actions. In Ajië, the middle prefix $v i$ - has reciprocal, reflexive, or collective meanings (the latter may be specified by the adjunct verhaya 'together'):

$$
\begin{aligned}
& \text { Curu bori we vi-kuru verhaya. } \\
& \text { 3DU SEQ COMPL vi-sleep together } \\
& \text { 'Then, they (two) slept together.' (Leenhardt 1932: 195) }
\end{aligned}
$$

The prefix alone may express reflexivity: na vi-jiwé 'he kills himself' (Aramiou et al. 2001); it may refer to an instantaneous, unexpected event: cue 'sit' > vi-cue 'sit suddenly' (La Fontinelle 1976: 239); it expresses durative, noncompleted aspects and derives deverbal nouns: rhôôru 'judge someone' $>v i$ rhôôru 'judgement' (Aramiou et al. 2001).

In Xârâcùù, the non-productive prefix $\grave{u}$ - is restricted to a few verbs. It refers (i) to collective and reciprocal actions with a few verbs with inherent collective or reciprocal meaning, such as 'gather, rejoice together, reconcile': ù-cuè 'gather' (cuè 'sit'); ̀̀-juu 'forgive each other' (juu 'agree'), (ii) to self-directed actions with verbs of grooming: ì-mwé 'bathe' (mwé 'plunge'); ù-cù 'comb

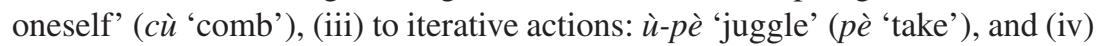

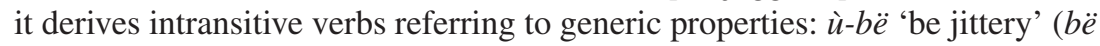
'move'); ไ̀-xù 'be contagious' (xù 'give') (Moyse-Faurie 1995: 182).

2.3.2. Coreferential transitive constructions. Since the M-prefixes are not very productive in the southern languages, various middle notions are encoded by transitive constructions with coreferential arguments expressing selfdirected actions $^{12}(11,12 \mathrm{a})$, reciprocal actions $(12 \mathrm{~b})$, agentless actions (deagentive function, 12c), including middle-passive (12d) and resulting states (13b). Adjuncts may appear for disambiguation. Transitive constructions with coreferential arguments thus take over the semantic range of the middle.

12. In Xârâcùù as in other New Caledonian languages, self-directed actions can be expressed by: (i) obligatorily intransitive verbs ('blow one's nose, hang, come undone, break, get lost, tilt'); (ii) intransitive constructions of labile verbs ('shave, gather'); (iii) obligatorily transitive verbs with coreferential arguments ('fail, succeed, shake, boast, writhe on the ground') (MoyseFaurie 1995: 77-79). 
(11) Ajië

Go cuи-ri-na $i$ mẽrẽ.

1SG put-TR-1SG INSTR clothes

'I dressed myself.' (Leenhardt 1935: 76)

(12)

Xârâcùù

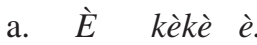

3sG bite 3sG

'He bites himself.' or: 'He bites him.' (Moyse-Faurie 1995: 77 78)

b. $\quad R i$ ciiwi ri.

3PL help 3PL

'They help one another.' or: 'They help them.' (Moyse-Faurie 1995: 77-78)

c. Nèxöö wâ sache è.

sky PERF cover 3sG

'The sky is getting overcast.' (Moyse-Faurie 1995: 77-78)

d. Nâ gwébasùù nâ xû oosi.

$1 \mathrm{Sg}$ shake 1SG on horse

'I'm shaken on the horse, lit. I shake me' (Moyse-Faurie 1995: $77-78)$

(13) Tîrî

a. U sevirro rò.

$1 \mathrm{SG}$ turn $1 \mathrm{sg}$

'I turned around.' (Osumi 1995: 255)

b. Peci hêrrê takîrrî nrî

paper IMPN wrinkle 3sG

'The paper is wrinkled.' (Osumi 1995: 256)

2.4. Northern and far northern languages of the mainland of New Caledonia

By contrast, in the northern languages, the reflexes of *paRi- are both very productive and polysemous (see Table 2), with some differences between the northern and far northern languages. The data originate from three well-documented languages: two of them, Bwatoo (Ehrhart \& Rivierre forthcoming) and Cemuhî (Rivierre 1980), are located in the centre-north, the third, Nêlêmwa (Bril 2002), is in the far north of the mainland.

2.4.1. Self-directed actions in Bwatoo and Cemuhî. In contrast with far northern languages such as Nêlêmwa, northern languages such as Bwatoo and Cemuhî display common features with southern and Loyalty Islands languages in that the M-prefixes may express self-directed actions (Cemuhî è pi-tim 'she's painting herself, making herself up' (timi 'paint'); Bwatoo a ve-xothit 'she looks at herself'), including grooming or change of posture (14). 
This is impossible in Nêlêmwa, where such self-directed meanings are expressed either by intransitive verbs ${ }^{13}$ ( $i$ bwaxexet 'he looks at himself') or by transitive verbs ${ }^{14}$ with coreferential arguments (as in Section 2.3.2), na pweedina 'I turn (myself)'.

In Bwatoo, the prefix ve- may combine with coreferential arguments:

$$
\begin{aligned}
& \text { Zho bwa ve-cubitaa-ong. } \\
& \text { 1SG DUR ve-turn-1SG } \\
& \text { 'I'm going to turn (myself).' (Ehrhart \& Rivierre forthcoming) }
\end{aligned}
$$

2.4.2. pe- in Nêlêmwa. Though the prefix pe-in Nêlêmwa has no reflexive meaning, it has a wide range of other meanings (summarized in Tables 2 and 3 , and detailed in Bril forthcoming) which fall under the basic notions repeated below:

(i) undifferentiated, collective arguments; reciprocal action; symmetrical relationship (Sections 2.6.1-3);

(ii) lack of agent or intentional initiator (as in spontaneous actions; Section 2.6.4.1);

(iii) lack of endpoint or goal (as in tentative, distributive actions; Section 2.6.4.2);

(iv) lack of aspectual endpoint (Section 2.6.4.3);

(v) intensive meaning (probably originating from plurality of relationships; Section 2.6.4.4).

Most of these meanings are attested in the other northern languages, as will be shown.

Given the polysemy of this morpheme in Nêlêmwa, some computation on a number of disambiguating factors is required, as well as the context, to allow its interpretation, including (a) the lexical category of the predicate (active verbs are potentially the most polysemous; stative verbs exclude the reciprocal and associative meanings; pronouns only accept the associative meaning, see Table 3); (b) argument number (a singular subject pronoun signals a non-reciprocal, non-collective meaning); (c) the semantics of the predicate (Sections 2.6.1 and 2.6.2); (d) the occurrence of the reciprocal (R-i) suffix (see Tables 4 and 5); (e) the occurrence of additional lexical adjuncts (Section 2.6.5);

$P e-\ldots-i$, a reflex of Proto-Oceanic *paRi-...-i which Nêlêmwa is the only Kanak language to have retained, is strictly restricted to reciprocal constructions with transitive verbs (Table 4) and to light, one-argument constructions, in which the reciprocal arguments are represented by nominals (15a) or only

13. Such as khet 'comb', hnet 'blow one's nose' (Bril 2000).

14. With a few verbs such as pweedi 'turn round'; bwagi 'retrace one's steps'; mwâaxi 'lie down'; fuugi 'gather' (Bril 2000). 


\section{$42 \quad$ Isabelle Bril}

Table 3. Meanings of Nêlêmwa pe- in relation to the lexical category of the root

\begin{tabular}{|c|c|c|c|c|}
\hline & $\begin{array}{l}\text { RECIPROCAL } \\
\text { subjects }\end{array}$ & $\begin{array}{l}\text { RECIPROCAL } \\
\text { objects }^{\mathrm{a}}\end{array}$ & $\begin{array}{l}\text { ASSOCIATIVE, } \\
\text { COLLECTIVE }\end{array}$ & $\begin{array}{c}\text { OTHER MEANINGS } \\
\text { (intensive, } \\
\text { dispersive, } \\
\text { spontaneous) }\end{array}$ \\
\hline$p e-+$ transitive verb & + & + & + & + \\
\hline$p e-+$ intransitive verb & + & $\varnothing$ & + & + \\
\hline$p e-+$ stative verb & comparison & $\varnothing$ & $\varnothing$ & + \\
\hline \multicolumn{5}{|l|}{$p e-+$ noun } \\
\hline in predicate function & comparison & $\varnothing$ & + & $\varnothing$ \\
\hline in argument function & + & $\varnothing$ & + & $\varnothing$ \\
\hline$p e-+$ pronouns $^{\mathrm{b}}$ & $\varnothing$ & $\varnothing$ & + & $\varnothing$ \\
\hline
\end{tabular}

a This refers to patients which are set in a symmetrical relation by an agent, as in 'he hit the metal pieces against each other'.

b Independent, deictic or anaphoric pronouns; $p e$ - is never prefixed to subject or object personal pronouns.

Table 4. Distribution of pe-...-i and reciprocal constructions in Nêlêmwa; + signals an existing construction; * ungrammatical or nonexistent construction

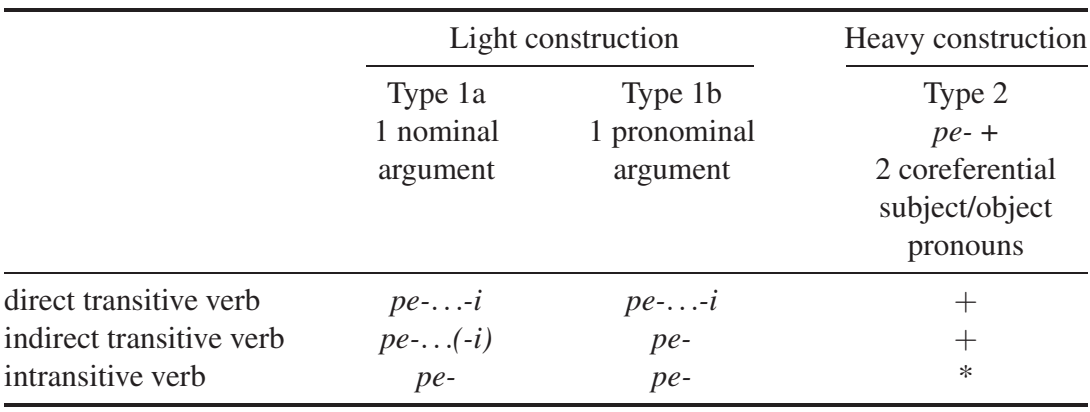

by dual or plural subject pronouns (15b) without any expressed coreferential patient (compare with $15 \mathrm{c})$. But the reciprocal suffix $(\mathrm{R}-i)^{15}$ does not appear in the heavy, two-argument construction marked by coreferential arguments (15c).

15. Since the reciprocal (R-i) suffix is homophonous with the transitive suffix, the best test to distinguish it is with inherently transitive verbs such as khua 'bite, eat up something', which lack the transitive suffix - $i$, as in hla khua-na 'they bit me'; compare with hla pe-xua-i 'they bit one another'. Other such verbs are cabwa 'pinch', thiwalaxa 'tickle', shêlâ 'know', ko 'chase', oxo 'follow'. 
Table 5. Distribution of pe-...-i; $\varnothing$ signals the absence of the $R-i$ suffix; $*$ signals an ungrammatical construction

\begin{tabular}{lccccc}
\hline & $\begin{array}{c}\text { RECIPROCAL } \\
\text { subjects }\end{array}$ & $\begin{array}{c}\text { RECIPROCAL } \\
\text { objects }^{\mathrm{a}}\end{array}$ & $\begin{array}{c}\text { ASSOCIATIVE, OTHER MEANINGS } \\
\text { COLLCTIVE } \\
\text { (intensive, } \\
\text { dispersive, } \\
\text { spontaneous) }\end{array}$ \\
\hline$p e-+$ transitive verb & $\mathrm{R}-i^{\mathrm{a}}$ & $\varnothing$ & $\varnothing$ & $\varnothing$ \\
$p e-+$ intransitive verb & $\varnothing$ & $*$ & $\varnothing$ & $\varnothing$ \\
\hline
\end{tabular}

a The reciprocal suffix is coded $\mathrm{R}-i$.

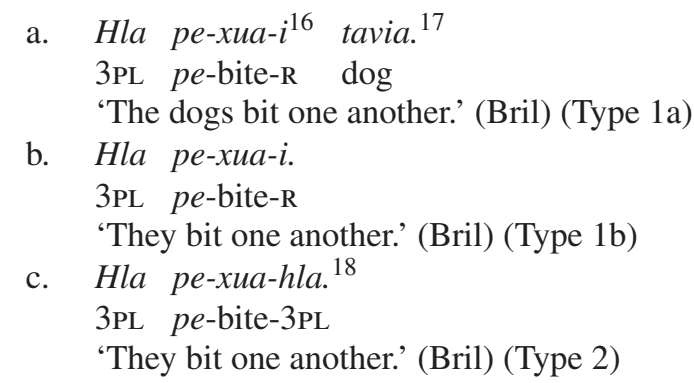

As Table 5 indicates, the R- $i$ (reciprocal) suffix disambiguates the reciprocal meanings from the other meanings of the prefix with transitive verbs.

\subsection{Light vs. heavy middle constructions}

The light construction consists of the prefix and one argument, whereas the heavy construction consists of the prefix and two coreferential arguments. While the heavy two-argument construction tends to have disambiguating functions (see (2)), the light construction tends to constitute the core of the middle domain with depatientive, deagentive functions, reference to a state or property of the subject, expressing "natural" reciprocity ${ }^{19}$ or self-directed actions with verbs of grooming. As Kemmer remarks, "the natural reciprocal and middle markers are never phonologically heavier than the marking for reflexives and [other types of] reciprocals" (1993: 120).

16. Intervocalic lenition: khua 'eat' > xua.

17. Compare with the canonical transitive construction with an ergative agent: hla khua-hla ru tavia [3PL bite-3PL AGT dog] 'the dogs [ERG] bit them'. Reciprocal constructions such as (26a) are intransitive; Nêlêmwa being a morphologically ergative language, the nominal reciprocal argument tavia is absolutive.

18. Compare with the non-coreferential meaning: hla khua-hla 'they bit them'

19. With "naturally" reciprocal verbs such as 'fight, meet, kiss, argue', etc. 
In Nêlêmwa (far north), the "light" one-argument strategy (type 1) is depatientive and refers to a single action involving several undifferentiated participants (16a, b); while the heavy strategy (type 2) with two coreferential arguments $\left(16 \mathrm{a}^{\prime}, \mathrm{b}^{\prime}\right)$ refers to several sequential actions reciprocally involving two or more participants:

\section{Type 1}

a. Hli

3DU pe-follow-R

'They (two) stand in line.'

b. Hla pe-kuluk

3PL pe-hide

'They play hide and seek.'
Type 2

a.' Hla pe-oxo-hla

3PL pe-follow-3PL

'They follow each other.'

b.' Hla pe-kulux-i hla

3PL pe-hide-REL 3PL

'They hide from each other.'

This correlates with Kemmer's (1993: 109) observation that "a light reciprocal marking is strongly associated with simultaneity, while heavy reciprocal markers are temporally indifferent". A light marker refers to states or to spontaneous events or actions with a low degree of distinguishability whereas "heavy reciprocal markers are associated with a higher degree of distinguishability of events" and participants (1993: 115).

The distinction is even clearer in other New Caledonian languages. Light constructions express the typical core middle functions and meanings found in Oceanic languages: Actor-oriented actions, depatientive function (18b-d), continuous actions without an endpoint (17b), distributive (18e), aimless actions (19c), reference to a property (20b). By contrast, the heavy constructions with two coreferential arguments stress symmetrical, sequential reciprocal actions, done in turns (17a, 18a, 19a, 20a) and sometimes self-directed actions (19b). Note that coreference obtains not just between the subject and object, but also between the subject and a possessive determiner (17a, 25b) or an indirect object (19a).

(17) Ajië (south of the mainland; La Fontinelle 1976: 238-239)

a. Curu vi-naa-be-ru.

3DU vi-give-companion-POSs.3DU

'They help each other.'

b. Curu vi-naa-be.

3DU vi-give-companion

'They help on and on.'

(18) Cemuhî (north of the mainland; Rivierre 1980: 258-262)

a. Lé pi-nua-lé.

3PL pi-cross-3PL

'They visit each other (across the mountain).' 
b. Lé pètaapwö pi-piidèn.

3PL each pi-separate

'They separate / go their own way.'

c. Lé pi-tai.

'They are in competition.' (tai 'chase, run after')

d. Lé pi-taunu.

'They are killing one another.' (taunu 'kill')

e. Lé tè ju pi-cèiu ne ko-li mii-n.

3PL ASS really $p i$-one on DEF.ART extremity-POSS.3sG

'There is one on each of his extremities.'

The prefix also appears on deverbal nouns with reciprocal or self-directed meaning: a pi-taunu 'the war'; a pi-ocit 'mirror' (ocit 'look (at oneself)') (Rivierre 1980: 262).

(19) Bwatoo (north of the mainland; Ehrhart \& Rivierre forthcoming)

a. Je ve-hme koo-je.

1PL.INCL ve-arrive to-1PL.INCL

'We meet each other.'

b. Zho ve-trake-ong pwa bala-triina.

$1 \mathrm{SG} v e$-throw-1SG on piece-wood

'I'm rocking (myself) on a piece of wood.'

c. Thira go ve-vadi!

Don't 2sG ve-work

'Do not play/fiddle around!' (vadi 'work, move')

(20) Iaai (Loyalty Islands; Ozanne-Rivierre 1976: 216-217)
a. Ödee ü-hlingöö-ödu köu.
3DU.PERF $\ddot{u}$-kill-3DU together
'They killed each other.'
b. A-me ü-lii seünö.
3sG(process) ü-burn sun
'The sun is scorching.' (lee 'burn something')

Similarly, in Fijian the light construction with only the M-prefix focuses on an activity, whereas the heavy construction expresses reciprocity (53).

2.6. The semantics of the reflexes of POc *paRi- in northern and far-northern New Caledonian languages

The M-prefixes in the northern languages show a broad range of polysemy.

2.6.1. Collective: Plurality of actors, grouping. Reference to collective actions or plurality of participants is very common and has various derived meanings: 
(21) Nêlêmwa
a. Hla pe-khuwo.
3PL pe-eat
'They eat together.' (Bril)
b. Pe-fââla-man ma ye.
pe-journey-1DU.EXCL COMIT 3sG
'He and I have travelled together.' (Bril)

With nouns or pronouns, the M-prefix also refers to symmetrical membership of a group (22a), to the collective/associative meaning (22b, c), or to partwhole relationships (pe-hmava-t 'patch-work' < hmava-t 'piece').

\section{(22) Nêlêmwa}
a. Pe-bala-hla.
pe-partner-POSs.3PL
'They are partners / in the same team.' (Bril)
b. Pe-hî (hada).
pe-1DU.INCL (only)
'We (two) together only.' (Bril)
c. Pe-hlaabai thaamwa, pe-hlaabai ak. pe-those.ANAPH woman pe-those.ANAPH man
'Those women together, those men together.' (Bril)

Distributivity and the reference to a mode of grouping also appear in other languages; the following examples refer to objects that are grouped in pairs, that generally come in pairs, or that stand in a symmetrical relationship (23b, 24):

(23) Bwatoo (Ehrhart \& Rivierre forthcoming)
a. Nyi ve-lu.
put ve-two
'Put two by two.'
b. Lu ve-jelan.
the. 2 ve-side
'the two door-frames'

(24) Cemuhî

Lupwö pi-duaa- $n$.
the. 2 pi-side-Poss.3sG
'the two sides of the hill' (Rivierre 1980: 262)

Malay and Indonesian ber- have similar functions (Section 3.1.2). 
2.6.2. Reciprocal. There are various subtypes of reciprocal situations with context-dependent interpretation, essentially filtered by verbal semantics. Subjects in reciprocal relation express a variety of meanings such as sequential reciprocity, competition, or chaining.

Sequential reciprocity and competition appear with verbs relating to games or social interaction. Constructions with coreferential arguments tend to refer to sequential actions and to disambiguate the reciprocal from the collective meaning. Again, note that subject coreference can be with an indirect argument (25a) or with the possessive determiner of the object (25b):

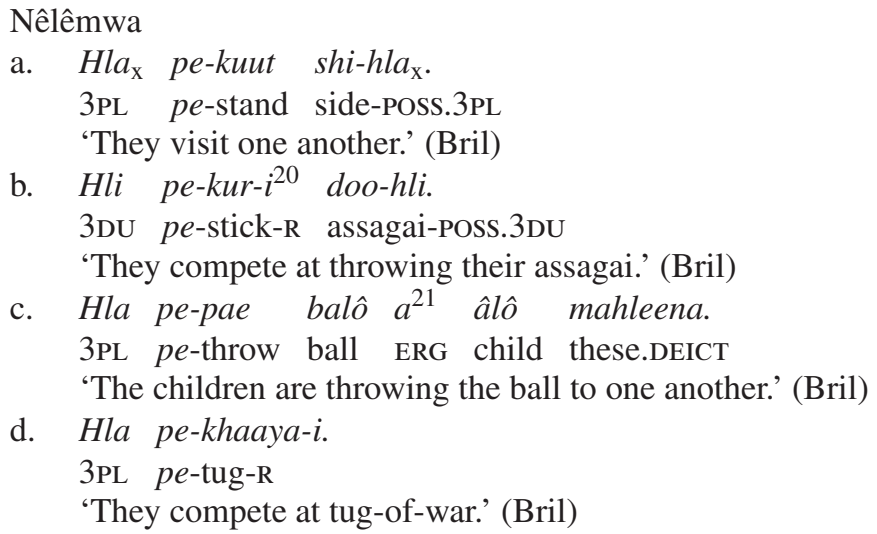

Compare with Fijian vei-dree 'pull each other; tug of war' (dree(-ta) 'pull'; Dixon 1988: 179).

Chaining (action done in a chain) constitutes a unique process which is not necessarily symmetrical nor reciprocal:

Nêlêmwa

Hla pe-oxo-i agu mahleeli.

3PL $p e$-follow-R people those.ANAPH

'These people walk in line.' (Bril)

Jawe

Dele te-pe-hulic.

3PL PREF(MOTION)-pe-follow

'They walk in line, follow each other.' (Haudricourt \& Rivierre 1982:

83)

20. Kure 'stick' is the transitive inflection for inanimate patients.

21. This is a canonical transitive construction with a patient (balô), an ergative agent (âlô), and VOS word order. 
As to object/patient reciprocals, patients in symmetrical relation essentially refer to notions of adjustment or union between them:

\section{(28) Nêlêmwa}

I pe-khi dooviu mahliili.

3sG pe-hit iron those2.ANAPH

'He hit the two metal pieces against each other.' (Bril)

(29) Bwatoo

A ve-cina xoot.

3SG ve-join rope

'He joins the two ends of the rope.' (Ehrhart \& Rivierre forthcoming)

2.6.3. Symmetrical relationship. Prefixed to nouns or pronouns in predicate or argument function, the M-prefixes express symmetrical relationship as well as collective action or plural relationship.

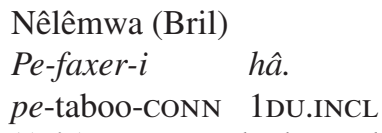

(31) Bwatoo (Ehrhart \& Rivierre forthcoming)

Le ve-hnyam.

3PL ve-love

'They pacify, love each other.' (hnyam 'peace, love')

2.6.3.1. Symmetrical kinship and dyadic relationship. Prefixed to nouns referring to kinship or relationship, they express a dyadic relationship, involving two or more persons.

(32) Bwatoo (Ehrhart \& Rivierre forthcoming)
a. ni tûûn a ve-bee-le
ART lineage REL ve-ally-POSs.3PL
'the lineages that are allies' (bee- $n$ 'sibling, ally, friend')
b. Lu $x a a^{22}-($ ve)-voona-n.
2DU PREF-(ve)-maternal.uncle-POSS.3SG
'the maternal uncle and his nephew'

(33) Caac (Hollyman 1971)

a. Pe-abaa-le.

pe-brother-POss.3PL

'They are brothers and sisters.'

22. Xaa is the prefix indicating reciprocal kinship terms. 
b. Pe-evi-le.

pe-sister-POSS.3PL

'They are first cousins.' or: 'They are (in a) paternal aunt and nephew/niece (relationship).'

In Fijian, vei- also refers to dyadic relationship, as in vei-wati-ni 'married couple'(wati 'spouse') (see Section 2.7). For similar cases in Formosan languages and in Tagalog see Section 3.1.

2.6.3.2. Symmetrical positions, locations, or properties. Symmetrical relations may also apply to position (34a), or more abstract notions, as in Nêlêmwa $p e$-avi-t 'fit, be adjusted to each other' (avi-t 'side, flank'), to location (34b), or to properties (35b).

\section{Nêlêmwa (Bril)}

a. Ma pe-aramaa-i.

1DU.INCL pe-face-R

'We are facing each other, lit. we are mutually face to face'

b. Pe-jeuk awôlô ma(h)leena.

pe-be.near dwelling these.DEICT

'These dwellings are close to one another.'

Compare with the non-symmetrical location: jeuk awôlô ma(h)leena 'these dwellings are close (to another reference point)'.

\section{Bwatoo (Ehrhart \& Rivierre forthcoming)}
a. $B u$
(ve)-cu-thamwa.

1DU.EXCL (ve)-stand-in.reverse

'We (two) stand back to back.'

b. Ve-thaten fwaadana-be.

$v e$-be.different road-POSS.1PL.EXCL

'Our roads are different (from each other).'

For similar relations in Fijian with distance and spatial relationships see Section 2.7 .

2.6.3.3. Comparison and symmetry. In the northern languages, when prefixed to nouns in predicative function or to stative verbs, the M-prefixes express comparison of equality between some entities which stand in a symmetrical relation with respect to a property, as in Nêlêmwa: pe-ida- $t$ 'be on the same line, of the same generation'(ida-t 'line, row'). A similar usage is attested in Mekeo (Section 2.7). 
(36) Nêlêmwa (Bril)

Wa pe-khooba-wa.

2PL pe-number-POss.2PL

'You are in equal number.'

(37) Bwatoo (Ehrhart \& Rivierre forthcoming)

Ve-hajoa-le.

ve-equal.number-Poss.3PL

'They are in equal number.'

Here are some further examples involving symmetrical quality or quantity (of age, size, appearance, etc.) in a variety of northern languages: ${ }^{23}$ Nêlêmwa peura-hli [pe-length-Poss.2DU] 'they (two) have the same length' (Bril); pe-kauhli [pe-year-Poss.2DU] 'they (two) are the same age' (Bril); Caac pe-weyile [pe-size-Poss.3PL] 'they are the same size' (Hollyman 1971); Cemuhî piwödè-lé [pe-generation-Poss.3PL] 'they belong to the same generation' (Rivierre 1980: 261).

2.6.3.4. Symmetrical point or space between some landmarks. In several languages, the prefix appears with a noun meaning 'centre, middle' in predicative function and refers to a symmetrical, middle point or space between two landmarks or objects, see (38) and (39); it may also refer to some middle position in kinship (neither the first nor the last born) as in Pwaamei/Pwâpwâ pe-fako [pe-middle] '(he is) the brother/child in the middle' (Haudricourt no date); Bwatoo ve-daboo- $n$ [ve-middle-Poss.3sG] '(he is) the (brother/child) in the middle' (Ehrhart \& Rivierre forthcoming).

\section{(38) Nêlêmwa}

ni pe-wooxa-t

in pe-middle

'(It is) in-between.' (Bril)

(39) Cemuhî

A pi-wième-n.

ART $p i$-middle-POss.3sG

'(It is) the one in-between.' (Rivierre 1980: 262)

In Bwatoo, ve- prefixed to the noun goo- $n$ 'size' in attributive function means 'be of medium size': balo ve-goo-n 'a medium sized ball'.

23. See Haveke ve-haaka-le 'they look alike/they have the same shape'; Bwatoo: ve-hamii-ju 'we (two) are identical, similar, equal'; le fe-ve-hamii-le [3PL CAUs-ve-similar-3Poss.PL] 'they imitate each other'. The nouns haaka in Haveke and hamii in Bwatoo are not autonomous but only occur in these constructions. Cemuhî: pi-jame-lé 'they are the same size' (jame 'size', -le 'their'). 
It is interesting to compare this meaning with the augmentative or attenuative meaning of the prefix in Drehu (Section 2.2.3) or its attenuative meaning in Cemuhî (46). Each of them originates from a different semantic domain of the prefix: the collective and augmentative meanings are closely related, while the attenuative meaning is probably related to the non-completed aspect (Section 2.6.4.3).

2.6.4. Other middle meanings. The third main semantic zone expressed by the reflexes of *paRi- is (i) when the two prototypical roles (agent/initiator and patient) are undifferentiated or when one of them is lacking, or (ii) when the process is unbounded and has no endpoint. In other Oceanic languages, such notions are commonly expressed by reduplication, but not in the northern New Caledonian languages where reduplication is rare (Cemuhî, Bwatoo) or nonproductive (Nêlêmwa).

2.6.4.1. Lack of intentional initiator: Spontaneous, unintentional actor, generic properties. The prefix refers to a spontaneous process which lacks an initiator or with an unintentional initiator (deagentive function, (40)), or it may refer to a process whose subject is the locus, not the initiator of the process (41). Alternately, the prefix denotes a generic predication referring to a property of the subject, not to an action.

\section{Nêlêmwa}

a. Pe-nuk du bwa doo pwâ-mago. pe-fall DIR on earth fruit-mango 'Mangoes are falling [because they are ripe].' (Bril)

b. Pe-â hwminy wi. pe-go here water 'The water flows here.' (Bril)

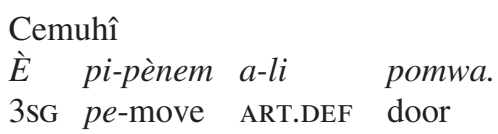

2.6.4.2. Lack of endpoint: Tentative, non-directed, dispersive action. All these meanings share the lack of endpoint. They express a tentative undertaking (42, 43a), an aimless, unintentional action, done listlessly (43b):

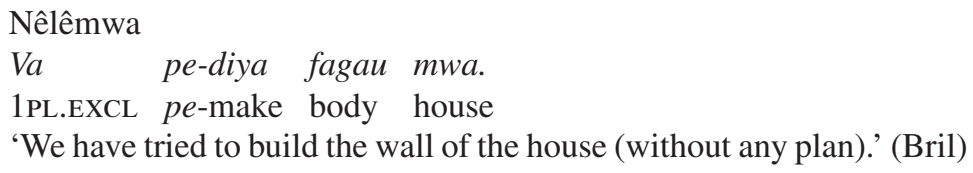


(43) Bwatoo (Ehrhart \& Rivierre forthcoming)
a. Zho ve-tataee koo-n.
1SG ve-surpass PREP-POSS.3SG
'I'm trying to surpass him.'
b. A ve-genu na Jean ko ani wang. 3SG $v e$-spend.time SM Jean PREP DEICT boat 'Jean is fiddling with the boat.'

With verbs of movement, the M-prefixes refer to dispersive, random, or directionless motion, meaning 'go here and there, take different directions' (44); Bwatoo le ve-tân 'they float, they are washed away with the tide' (tân 'hop, jump'); Cemuhî pi-èngen 'loiter' (èngen 'walk') (Rivierre 1980: 259).

\section{Nêlêmwa}

Bu na xe na gaa pe-haga du hmwiny.

EXPL 1SG TOP 1SG PROG pe-fish down here

'As for me, I'm going to go on fishing around here (with no specific intention of catching any specific type of fish in any precise place).' (Bril)

2.6.4.3. Lack of endpoint: Unbounded, non-completed, durative actions.

Non-completed and durative actions also lack an endpoint; this correlates with a non-fully affected patient. The non-completed meaning of the prefix appears in several northern languages, Nemi (Ozanne-Rivierre 1979), Bwatoo (45), and Cemuhî.

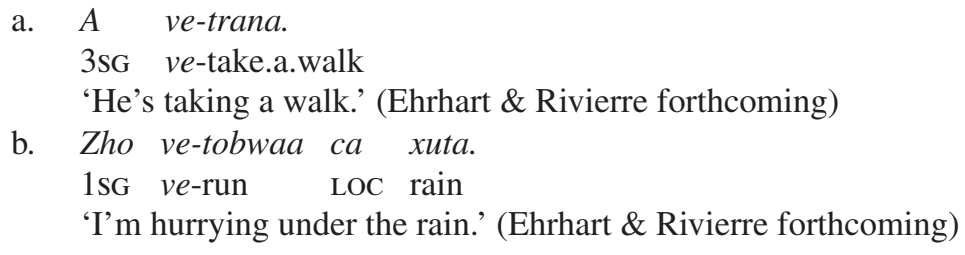

In Cemuhî, pi- may derive an unbounded process from a state (è pi-wahîn 'he is losing weight' [wahîn 'small']), it may refer to iterative (è pi-cing 'he stumbles' [cing 'collapse']) or non-completed actions which may carry attenuative meaning ${ }^{24}(46)$.

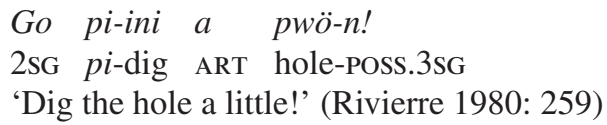

24. pi-abé 'approach a little' (abé 'come'); pi-cèi-hî 'empty a little, half empty'(cèi-hî̀ 'empty

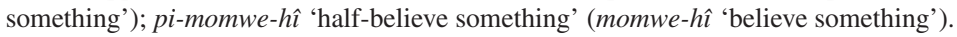


A similar attenuative usage is seen in Toqabaqita: Kwai-karangi! 'Move close(r)!' (karangi 'approach') (Lichtenberk 2000: 47).

2.6.4.4. Lack of endpoint and plurality of relations: From iteration to intensity. In New Caledonian languages, the M-prefixes often express iteration, degree, and intensity (cf. the augmentative meaning of the prefix with nouns in Drehu, Section 2.2.3.1). Such semantic extensions might stem from two of their basic notions, plurality of relations and iteration, which are inherent to reciprocal actions. This might in turn give rise to notions of intensity (from 'do together' and 'do repeatedly' to 'do quickly, intensely'). In many Austronesian languages, intensity is expressed by reduplication. Here are some examples of iterated actions: Nêlêmwa $i$ pe-thalic [3SG pe-stumble] 'she stumbles over and over again' (Bril); Bwatoo ve-tûûn 'move out, change places frequently' (tûûn 'move out'); ve-cotree 'be crowded, jostle, make one's way through' (cotree 'push'). (47) gives some examples of the intensive meaning of pe-in Nêlêmwa, translating as 'fast, quickly'.

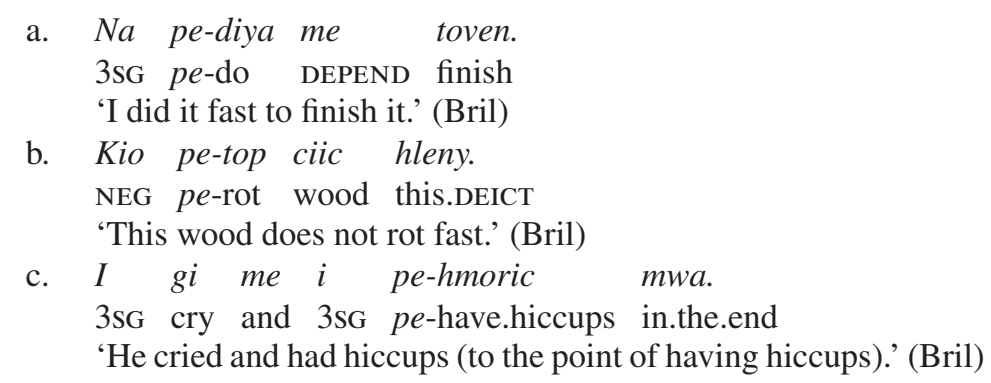

2.6.5. Ambiguity and lexical disambiguation in New Caledonian languages. Given the polysemy of these M-prefixes, various other morphemes or lexical adjuncts are used for disambiguation, with some differences from the north to the south of the mainland. In the Loyalty Islands and in the south of the mainland, the prefix is basically a middle marker whose extended reciprocal or collective meanings are generally specified by an additional morpheme meaning 'together'. By contrast, most northern languages tend to use additional lexemes to specify all the other meanings except the reciprocal meaning.

2.6.5.1. 'Together': Lexical expression of collective meaning. In ambiguous cases such as (48a), which may be interpreted as collective or intensive, the collective meaning may be disambiguated by an adjunct meaning 'together': wuung in Nêlêmwa, thipo in Bwatoo (49a). 
(48) Nêlêmwa

a. Hâ pe-shaya. ${ }^{25}$

1PL.INCL $p e$-work

'We work fast.' or: 'We work together.' (Bril)

b. Hâ pe-shaya wuung. ${ }^{26}$

1PL.INCL $p e$-work together

'We work together.' (Bril)

In Bwatoo, thipo selects the collective meaning rather than the default middle meaning of the prefix; see (49) from Ehrhart \& Rivierre (forthcoming).
a. A ve-trana ${ }^{27}$ pwa mat.
3SG ve-take.a.walk on low.tide
'He strolls on the shore at low tide (aimlessly).'
b. $\quad J u \quad$ ve-trana thipo.
1DU.INCL ve-go.for.a.walk together
'We (two) are going for a walk together.

2.6.5.2. 'Aimlessly', 'different': Lexical expression of randomness or dispersive meaning. Example (50a) from Nêlêmwa may have either a tentative or a collective reading, with the adjunct hayu 'haphazardly, carelessly, aimlessly' in (50b) disambiguating the notion of aimlessness.
a. $\quad V a$
pe-diya fagau mwa.
1PL.EXCL pe-do body house

'We tried to build the wall of the house (tentative).' or: 'We built together the wall of the house.' (Bril)

b. Va pe-diya-ayu-lî.

1PL.EXCL pe-do-carelessly-TR

'We did it carelessly.' (the initial /h/ of hayu is deleted in intervocalic position)

In Bwatoo, thaten 'be different' also helps select the dispersive meaning; see (51) from Ehrhart \& Rivierre (forthcoming).

$$
\begin{aligned}
& \text { Bu daara ve-nyi thaten. } \\
& \text { 1DU.EXCL each ve-put be.different } \\
& \text { 'Each of us puts (his packet) separately.' }
\end{aligned}
$$

\footnotetext{
25. As in other Kanak languages, shaya has the double meaning of 'move' and 'work'.

26. Derived from fuung 'gather, pile'.

27. Trana 'take a walk' is a modest way of saying 'go fishing, go hunting' in order to avoid a bad catch.
} 
2.6.5.3. 'Alone': Lexical expression of solipsistic, separative meaning. In Nêlêmwa, the adjunct hada 'alone, only' in $i$ pe-vhaa hada selects the solipsistic meaning (do by oneself, on one's own): 'he speaks for himself, on his behalf, i.e., in his own name, not expressing a consensus', ${ }^{28}$ while $i$ pe-vhaa may have intensive, durative, or solipsistic readings: 'he speaks and speaks' or 'he speaks for himself'. Compare with the mere restrictive meaning of $i$ vhaa hada 'he alone is speaking'.

Rather than being a "limiting case of the collective sense" (McGregor 2000), this semantic extension might originate from the notion of self-directedness, which gives rise to reflexivity in some languages and to the solipsistic reading in others. It might also stem from the spontaneous reading and the decausative function of the prefix (Section 2.6.4.1), as in (40a): the mangoes are falling by themselves, without being made to fall.

Further such examples of disambiguation are seen Mwotlap and Toqabaqita (Section 3.2.4).

\subsection{Comparison of the reflexes of POc *paRi- in various Oceanic languages}

Similarly polysemous and polyfunctional reflexes of POc *paRi- exist in other Oceanic languages from different subgroups: BI- in Mekeo (Western Oceanic, Papua New Guinea), vei- in Fijian (Central Pacific), vēi- in Mwotlap (Remote Oceanic), fe- in Futunan (Polynesian).

2.7.1. Mekeo BI-. Mekeo (Jones 1998: 374-380) has a prefix BI- (representing various dialectal allomorphs $\beta i-, b i-, p i-)$ which has a strikingly similar number of functions and meanings correlating with intransitive or transitive verb classes. It expresses cooperative, collective actions involving a plurality of subjects, reciprocal, symmetrical relationship, as well as iterativity, intensity, or habitual aspect. Combined with the suffix -AI (a reflex of Proto-Oceanic

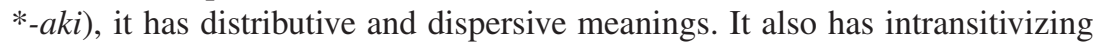
functions and refers to states and properties, in particular with reduplicated roots, as in pi-ani-ani 'cannibal ogre' ( $<$ ani 'eat'). When it is prefixed to nouns in predicative function such as kobo 'measure', it expresses comparison of equality: au ike pi-kobo iu go [man this REC-measure me like] 'this man is like me' (Jones 1998: 207) (see Section 2.6.3.3 for similar examples in New Caledonian languages). These functions and meanings reflect those listed for Oceanic languages in Table 1.

28. In Yawuru (Nyulnyulan family, Australia), the reciprocal-reflexive-collective affixes ma...-nyji have a similar (though infrequent) meaning 'by oneself, alone, on one's own', which McGregor (2000: 114) analyses as a limiting case of the collective sense. The more frequent strategy is to use the adverbial ngurdirn 'alone' 
2.7.2. Fijian vei-. The Fijian prefix vei- (Milner 1972: 112-113) is similarly polysemous and polyfunctional. Apart from reference to collective entities or to modes of grouping as in vei-vale '(various, all sorts of) houses', na vei-niu 'coconut plantation' (< niu 'coconut'), vei-kau 'forest' (< kau 'tree') (Dixon 1988: 176), the prefix also has distributive meaning as in na vei-mataka 'each, every morning' (Milner 1972: 16, Schütz 1985: 365), it refers to reciprocal kinship (52a), to symmetrical or similar position in space (adjacent position, close to each other; see Schütz 1985: 207 and (52b, c)). With verbs, the prefix refers to reciprocal or collective activities involving two or more participants (52d).

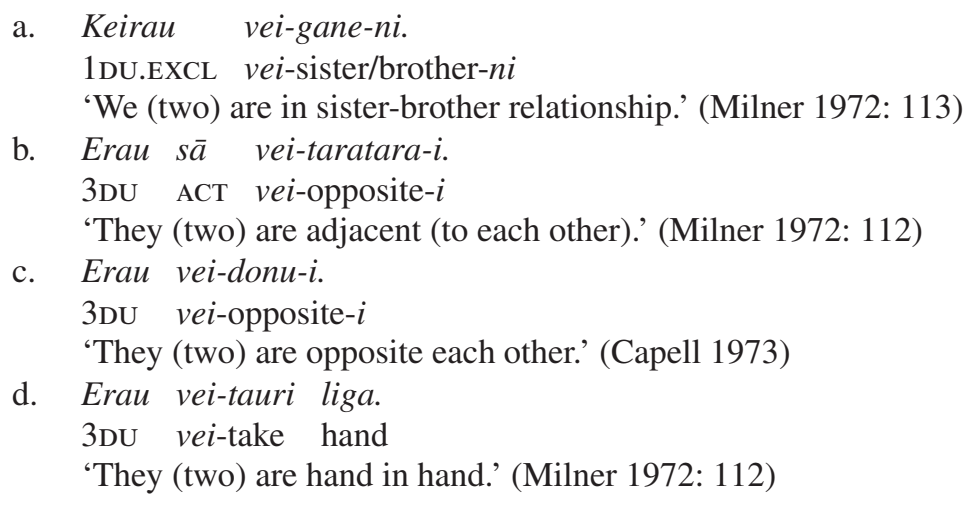

It also derives deverbal nouns of action as in vei-vorati 'mutual opposition' $(<$ vora-ta 'withstand'; Capell 1972) or vei-bulu 'burial' (< bulu 'bury'; Schütz 1985: 211) or it derives intransitivized verbs (Dixon 1988: 176).

Schütz (1985) and Dixon (1988: 180) note a focus on activity and on the depatientive function (absence of goal or patient) (53a-c), a global reference to the participants which "avoids topicalizing either one of the participants" as in (53c) (in which Mary nurses the child with no reciprocity involved), as well as a reference to generic properties or habitual action (53d). The light construction with the prefix alone focuses on an activity (53e), whereas the construction combining a prefix and a suffix (53f) expresses reciprocity.

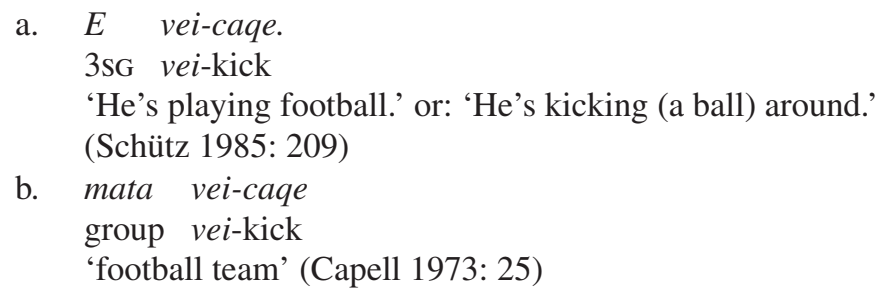




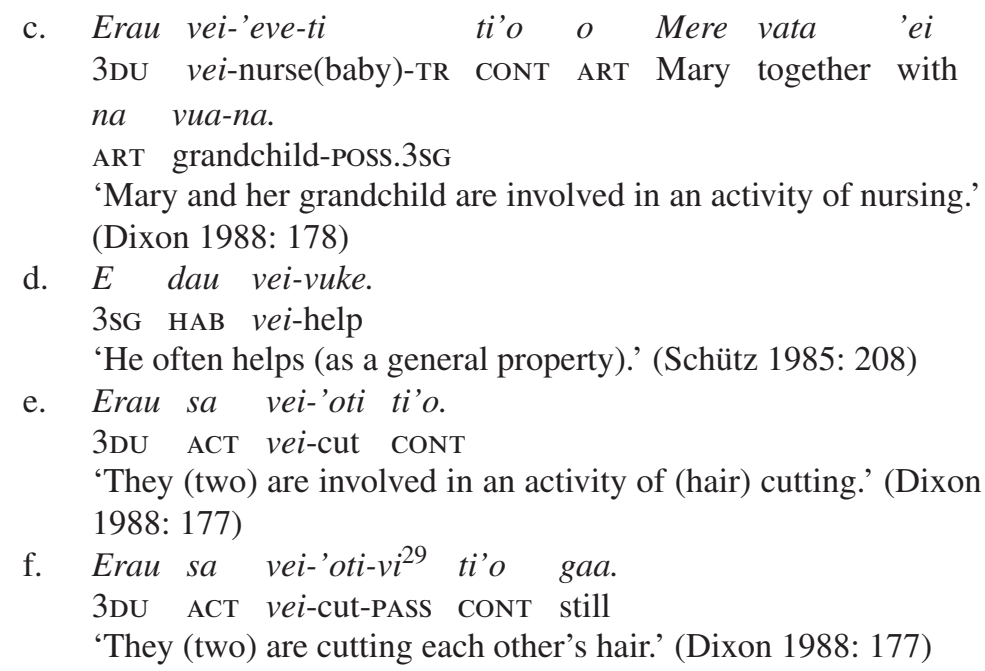

As for dispersive actions (done in all directions) or reversive actions (back and forth), they are expressed by the combined morphemes vei-...-yak(i) (Milner 1972: 113, Schütz 1985: 208). Reflexives are marked by coreferential subject and object pronouns (Dixon 1988: 255).

2.7.3. Mwotlap vēi- and Futunan fe-. In Mwotlap (Vanuatu; François 2001: 250-251), the non-productive prefix vey-y-expresses reciprocity, intensity, or competition (Section 3.2.4). In Futunan (Moyse-Faurie forthcoming a), the prefix $f e$ - expresses reciprocity with dual or plural pronouns $(f e$-tuli 'chase each other'), but it has intensive meaning with singular pronouns (e kau fe-tuli [NONCOMPL 1sG fe-follow] 'I'm hurrying up').

\section{The proliferation of middle and derived meanings of the reflexes of POc *paRi- in New Caledonian languages: Hypotheses and compara- tive data}

This section investigates the reasons for the extended polysemy of the middle prefixes in northern New Caledonian languages. A striking fact when one investigates other Austronesian languages (both Oceanic and non-Oceanic) is that, when they remain productive, these prefixes have a core of common functions and meanings (reciprocal, collective, depatientive), though of course with some variations. Some Oceanic languages also appear to combine the

29. "Adding a passive suffix to a vei-form with this verb implies that each participant is alternately agent and patient, that is, each one does it to the other" (Dixon 1988: 178). 
M-prefixes with reduplication (Section 3.2.1) to express plurality of relations, intensive, iterative, non-completed, intransitivization, etc. (Table 1, Sections 3.1 and 3.2.1), while in others, such notions are marked by reduplication alone (Section 3.2.2). Thus reduplication, whether combined with the M-prefixes or not, has a heavy functional load.

A second striking fact is that in New Caledonian languages, reduplication ranges from not very productive to nonexistent in some languages (Section 3.2.3). Thus, the hypothesis to be put to the test is that at least some aspects of the polysemy of the reflexes of Proto-Oceanic *paRi- in northern New Caledonian languages might result from the loss of their combined suffixes (POc *-i, *-aki), the decay or loss of reduplication (Nêlêmwa, Bwatoo, Cemuhî, Section 3.2.3), and from the conflation of these different meanings onto the preserved prefix. In the southern New Caledonian languages, where even the reflexes of *paRi- are no longer productive or decayed, those meanings are distributed over different constructions and strategies (Section 3.2.3).

\subsection{M-prefixes and reduplication in non-Oceanic Austronesian languages}

Reduplication is a common and polysemous device in Austronesian languages (Blust 1988, Himmelmann forthcoming a). Among its most frequent meanings are plurality and variety of relations or types ('all sorts of'), collective action, intensive, iterative, distributive, dispersive actions. In Indonesian, reduplication also expresses duration or suddenness, an aimless action, done without energy, tentatively as in jalan-jalan 'stroll, take a walk' ( $<$ jalan 'walk'; Lombard 1977: 69, 104).

In Austronesian languages, the M-prefixes often combine with reduplicated bases to express plural relationship, plural participants ('do together'), intensive and distributive actions. This is attested in Malayo-Polynesian languages (Section 3.2.2), and in Oceanic languages such as Mekeo, Fijian (Milner 1972: 112), or Samoan (Milner 1966) (Table 1 and Section 3.2.1). Let us first analyse the case of non-Oceanic Austronesian languages.

3.1.1. Formosan languages. In Formosan languages such as Puyuma, Paiwan, and Rukai (Zeitoun 2002), the reciprocal prefixes ma(r)-, pa(r)- (Section 1.2) combine with root reduplication to indicate a plurality of participants in reciprocal relation.

In Paiwan, may- $\sim$ pay- combined with Ca-reduplication (for active verbs) refer to two participants, as in may-ta-təvəla $\sim$ pay-ta-təvəla 'answer each other' (from $t$-əm-vəla 'answer'), while may- $\sim$ pay- combined with Ca-reduplication AND root reduplication refer to plural participants: may-ta-təvəla-vəla $\sim$ pay-ta-təvəla-təvəla 'answer one another'. Similar facts occur in Puyuma with, for instance, mar-pa-na?u $\sim$ par-pa-na?u 'look at each other' and mar- 
pa-na?u-na?u par-pa-na?u-na?u 'look at one another' (pa-causative, na?u 'look').

With kinship terms, the prefixes express reciprocal kinship and reduplica-

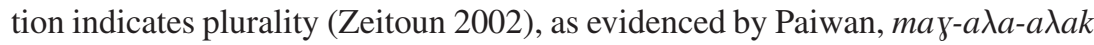
'parent and children' ( $a \lambda a k$ 'child'); by Puyuma, mar-taina 'mother and daughter', mar-taina-ina 'mother and daughters' (taina 'mother'), mar-kartaguin 'couple, husband and wife' (kartaguin 'spouse'), mar-kartagukaguin 'many couples'; by Rukai, ma?a-tama pa?a-tama 'father and son/daughter' (tama 'father'), la ${ }^{30}$-ma?a-tama-tama 'father and sons/daughters', ma?a-tomo pa?a-tomo 'grandfather and grandchild' (tomo 'grand-parent'), la-ma?a-tomotomo 'grandfather and grandchildren'.

3.1.2. Malayo-Polynesian languages. In Tagalog, the polysemous prefix mag- (Section 1.2) combined with reduplication expresses intensity (takbo 'run' $>$ mag-ta-takbo 'run wild' (Lopez 1940: 103, Schachter 1987: 950) or attenuation (lakad 'walk' > mag-lakád-lakád 'do a little walking', Himmelmann forthcoming a), two semantic features carried by the prefixes in New Caledonian languages. With kinship terms, the prefixes express dyadic kinship, mag-ama 'mother and child', mag-anak 'parent and child', or reciprocal relationship, mag-kaibigan 'be friends' (Schachter \& Otanes 1972: 293), whereas the prefix combined with root reduplication indicates plural relationship, as in mag-pi-pinsan '(relation between) several cousins' (Schachter \& Otanes 1972: 102).

In Malay and Indonesian, the prefix ber-, which is a reflex of the ProtoMalayo-Polynesian actor focus voice $*_{m a R}-{ }^{31}$ may be used alone or combined with reduplicated bases.

Without root reduplication, ber- in Malay (Hassan 1974: 109-110) and Indonesian (Lombard 1977: 111-114, 116, 140) expresses collective action or plurality of actions, reciprocal relationship (kelahi 'quarrel' $>$ ber-kelahi 'quarrel with one another'), and self-directed actions (ber-cukur 'shave oneself').

30. In Rukai, "prefixed by ma?a- a noun can function as a nominal predicate, marked by la-ma?aa noun can only function as an argument" (Zeitoun 2000).

31. Modern Malay ber- is a reflex of the Proto-Malayo-Polynesian prefix *maR- which originates from the fusion of the actor focus voice infix $-U M$ - and the prefix *paR- $\left(\langle * u m\rangle+{ }^{*} p a R-\right)$. Both *maR- and *paR- are actor focus voice markers. PMP *paR-occurred in dependent or imperative verb forms, in nouns and adjectives and also carried durative and intensive meanings. PMP *maR- formed independent, neutral, indicative verb forms (Reid \& Liao 2004, Ross forthcoming). The change from PMP *maR- to Malay ber-is due to the neutralization of the vowel before stress and the appearance of an epenthetic $\langle\mathrm{b}\rangle$ in $\operatorname{mar}-\left({ }^{*} m a R->* m(e) r-\right.$ $>* m b(e) r->$ ber-; Adelaar 1984, 1992). The function of Proto-Malayic *bAr- $(>b e r-)$ was to form intransitive, actor focus voice including middle voice, while *pAr- (> per-) formed transitive undergoer focus voice. Proto Oceanic (POc) *paRi- reflects PMP *paR- (Reid 1987, Ross personal communication). 
It derives middle intransitive verbs whose initiator (decausative function) or endpoint (depatientive function or non-completed aspect) is lacking. These active intransitive verbs may be derived from transitive verbs (jual 'to trade' $>$ dia berjual kuda 'he trades horses' as a generic activity; Lombard 1977: 114), from stative verbs (Indonesian jahat 'be bad' > ber-jahat 'act badly'; Lombard 1977: 113), from nouns (Indonesian and Malay: kuli 'a worker' > ber-kuli 'work as a coolie'; mimpi 'a dream' > ber-mimpi 'to dream'; buah 'fruit' > ber-buah 'to produce fruit'). These derived verbs or predicates often refer to a generic activity or a property (warna 'colour' > ber-warna 'be coloured'). Indonesian ber-prefixed to a numeral also refers to a mode of grouping (ber-dua 'both, the two of $\mathrm{x}$ together', ber-tiga 'the three of').

Combined with root reduplication, it refers to a plurality of entities or types (ber-warna-warna 'multicoloured' < ber-warna 'be coloured') or to distributive modes of grouping (ber-ratus-ratus 'by hundreds'); it also expresses aimless, non-completed activities as in Indonesian ber-malas-(malas) 'be idle, loiter, laze around' (< malas 'lazy'; Lombard 1977: 112-113).

The not very productive circumfix ber-...-an in Malay and Indonesian also combines with reduplication to express an iterated reciprocal relationship (Malay ber-tikam-tikam-an 'stab one another repeatedly'), or intensity (bersuka-suka-an 'celebrate away (a wedding)'), or a dispersive meaning (Malay ber-lari-lari-an 'escape in all directions'; Hassan 1974: 110).

\subsection{The reflexes of $P O c *$ paRi- and reduplication in Oceanic languages}

Turning to the functions and meanings of reduplication in Oceanic languages, it is seen to have different degrees of productivity and polyfunctionality: it is particularly productive and polysemous in Micronesian languages (Bender 1971, Harrison 1973) and in some other Oceanic languages (Section 3.2.1). Reduplication generally indicates plurality of relationship, collective actions, noncompleted, iterative or habitual actions, stative properties, tentative, distributive, separative, random actions, but it also expresses intensity, augmentation or diminution/attenuation, comparison of similarity. It also has intransitivizing and nominalizing functions. Interestingly, such functions and meanings are partly similar to those of the reflexes of POc *paRi- in the northern New Caledonian languages, where reduplication is not productive. In Oceanic languages, the reflexes of $* p a R i$ - and reduplication may combine (Mekeo, Samoan, Fijian, Section 3.2.1), or they may constitute complementary derivations each with specific meanings and functions (Section 3.2.2).

3.2.1. Combination of the reflexes of $P O c *$ paRi- and reduplication. In Mekeo (Jones 1998: 377-378, 397-400), the prefix BI- combined with root reduplication refers to a property, as in pi-ani-ani 'cannibal ogre' ( $<$ ani 'eat'), 
and expresses repetition and intensity. The prefix itself may be reduplicated as in ke pi-pi-kafa [3PL REC-REC-insult] 'they went on exchanging insults' $(<p i$ $k a f a$ 'insult one another'). Besides, BI- and reduplication ${ }^{32}$ often overlap for the expression of iterative and habitual meanings, although, for the latter, $B I$ is most common with intransitive verbs.

In Samoan (Milner 1966, Mosel \& Hovdhaugen 1992: 180-183), fe-...-i may combine with a reduplicated base to express plurality of relationship, reciprocal, dispersive actions (carried out here and there, up and down, hither and thither, all around), intensive actions (carried out quickly), etc.

In Fijian, the polysemous prefix vei- (Section 2.7) and reduplication may combine or be used separately with distinct functions and meanings. Vei- combined with a reduplicated verb expresses reciprocity and/or plurality of relationship as in erau vei-taqataqa- $i$ 'they are lying on top of each other' ( $<$ taqa (-ra) 'put something laying over another thing'; Milner 1972: 112-113), as well as multiple actions and multiple participants to an action as in vei-taratara-vi 'follow each other' (< tara-va 'follow'; Dixon 1988: 178). Combined with partial reduplication, it expresses alternate actions: thus vei-sii.sivi $(<$ siivi(-ta) 'pass, exceed') refers to persons going in the same direction and alternately passing each other, whereas vei-sivi(-ti) is used for a single event, with persons passing each other once from opposite directions.

Combined with a reduplicated noun form, vei- carries reciprocal, collective ('together') meaning, as in vei-dokadoka-i 'mutual respect' ( $<$ doka 'honour, respect'; Milner 1972: 112), or it conveys the notion of plurality or totality, compare vei-vale '(various) houses' and vei-valevale 'every house' (Dixon 1988: 176-177, 198).

The prefix and reduplication also have distinct functions and meanings. With nouns, the prefix marks an abstract nominal referring to an activity or occupation (vei-sele 'surgical operation'), while reduplication refers to a part or result of that activity (selesele 'a cutting, a piece cut off'; Schütz 1985: 210).

Reduplication also derives intransitive or stative predicates from transitive verbs to express properties as in savasava-a 'be clean' < sava-ta 'wash (transitive)' (Capell 1973); a reduplicated verb form is thus normally intransitive (Dixon 1988: 48). Reduplication also carries intensive meaning (e culacula 'she is sewing away'; Dixon 1988: 198), it expresses frequentative, iterative, durative actions carried out over a long period (raberabe 'do a lot of kicking'; Milner 1972: 48), it also refers to a totality, a whole ( $v \bar{a}$ 'four' $>v \bar{a} v \bar{a}$ 'all four').

32. Reduplication of nominal roots carries a variety of other meanings: diminutive (small), pejorative, hypocoristic, intensifying, plurality, multiplicity, abundance, generality/abstractness (Jones 1998: 137-141) 
3.2.2. Complementary distribution of the reflexes of POc *paRi- and reduplication. In other Oceanic languages, neither the reflexes of *paRi- nor reduplication are very productive, polysemous, or polyfunctional; nor do they combine, they have distinct functions and meanings.

In Manam (Lichtenberk 1983: 211-214), the prefix $e-\ldots(-i)$ expresses reciprocity, while reduplication marks continuative, progressive, persistive actions, or derives deverbal agentive nouns (pile 'speak' > pilepile 'speaker') and adjectives expressing properties and resulting states (zama 'tomorrow' $>z a$ mazama 'pertaining to tomorrow', zo?u 'bend (transitive)' > zo ?uzo ?u 'bent'; Lichtenberk 1983: 609-612).

In Tolai (Mosel 1984: 146-147), the middle prefix var-expresses reciprocity and is also an intransitivizing (depatientive) morpheme: kara- 'bite something' $>$ var-karat 'bite (intransitive)'; korot 'chase something' > var-korot 'perform the action of chasing'. On the other hand, reduplication expresses plurality, collective, distributive, intensive actions, as well as non-completed, durative, progressive, iterative, and habitual actions; it also refers to states and properties (Mosel 1984: 96-102). As often in Oceanic languages, partial and full reduplication have different functions and properties; in Tolai, partial reduplication is intransitivizing ( $k i t a$ 'to hit something' $>$ kikita 'hit (intransitive)'), while full reduplication refers to non-completed actions (kitakita 'to be hitting someone' (1984: 93)). As for reflexives, they are marked by coreferential arguments (1984: 145).

In Futunan (Moyse-Faurie forthcoming b), the middle prefix and reduplication do not quite overlap either: the middle prefix $f e-\ldots(-i,-a k i)$ expresses reciprocal, collective, intensive meanings, while reduplication expresses iterative, intensive, diminutive, and reflexive meanings (restricted to a few verbs such as selu 'comb someone' $>$ seluselu 'comb oneself', tilo 'look at someone' $>$ tilotilo 'look at oneself'). Reduplication also derives intransitive verbs (depatientive function). These derivational devices only apply to small verb classes.

3.2.3. Non-productive reduplication in New Caledonian languages. As already mentioned, reduplication is generally no longer very productive in New Caledonian languages. Hagège \& Haudricourt (1978), Ozanne-Rivierre (1986), and Rivierre (1993: 159-160) have shown that former reduplication gave rise to aspirate stops in the northern ${ }^{33}$ languages and the Loyalty Islands languages and to high tones in the southern languages. Yet, in the Loyalty Islands and in Xârâcùù (south), renewed reduplication has some productivity and a range of

33. There are new reduplicated forms in some of these languages, but the device is not as productive as it is in other Oceanic languages. 
meanings similar to those marked by the middle prefixes in the northern languages, which are characterized by non-productive or nonexistent reduplication. Where attested, reduplication in New Caledonian languages generally expresses iterativity, intensity, plurality, or collective action; other meanings tend to be areal or language-specific. Secondly, the M-prefixes and reduplication tend not to combine, but to be in complementary distribution; thus, the original pattern of combination has been lost with renewed reduplication. I chanced upon only one example of such a combination in my Nêlêmwa corpus: hla pe-wuwudi-â (< pudi 'surround') 'they surrounded us', where reduplication conveys the notion of a great number of participants and of intensity.

Northern New Caledonian languages show a striking correlation between the productivity and polysemy of the reflexes of Proto-Oceanic *paRi- and non-productive (Nêlêmwa, Nyelâyu) or rare (Bwatoo, Cemuhî) reduplication. These middle prefixes conflate almost all the meanings and functions which are expressed by other combined morphological devices or other constructions elsewhere in New Caledonian languages, thus triggering the need for disambiguating morphemes or adjuncts (Section 2.6.5). Where the M-prefixes and reduplication coexist, they do not combine and there is little overlap between their meanings and functions. Reduplication essentially refers to plurality and variety of types, intensity, iterativity and, in a lesser degree, to inchoative or non-completed actions.

In some southern languages (Ajië, Tîrî), neither reduplication nor the reflexes of POc *paRi- are very productive. In Tîrî (Osumi 1995: 134) where the M-prefixes are decayed, only a few cases of reduplication with mostly intensive and augmentative meanings are attested. In Xârâcùù (Moyse-Faurie 1995), the M-prefixes are residual but reduplication is more productive and expresses intensive and dispersive meanings.

Thus, in the southern languages, the reciprocal, reflexive, and other middle notions are expressed by resorting to transitive constructions with coreferential arguments (Section 2.3.2, (11)-(13)). In Ajië, the transitive coreferential construction expresses self-directed actions, while reciprocity is marked by the prefix vi-combined with coreferential pronouns (cf. 11, 17a). For a similar situation in Mwotlap (Vanuatu) see Section 3.2.4.

The languages of the Loyalty Islands use M-prefixes, transitive constructions with coreferential arguments, and reduplication. The M-prefixes may combine with coreferential arguments (for reflexive, reciprocal meanings), but they do not usually combine with reduplication. ${ }^{34}$ There is some functional and semantic overlap between the M-prefixes and reduplication: in all the languages

34. Though there are a few occurrences of such combination, as in i-jeajea 'separate, meet (on the way)' (< jea 'turn, take different paths, branch off'; Sam 1995: 86). 
of the Loyalty Islands, Drehu, Iaai, East Uvean (Ozanne-Rivierre 1986: 47), and Nengone, reduplication or the M-prefixes derive stative verbs referring to properties and have intransitivizing function. In Drehu (Moyse-Faurie 1983: 134-137), reduplication or the prefix $i$ - has augmentative or diminutive meaning. In Iaai and Nengone (Cawa 2000: 286-287), reduplication also has specific functions and meanings: it expresses non-completed, iterative, and frequentative actions and has dispersive and distributive meaning.

These data suggest different types of evolution with a rough areal distribution. First, in the northern New Caledonian languages, the broad polysemy of the reflexes of POc *paRi- strongly correlates with the loss of combined reduplication (a pattern found in other Oceanic languages and traceable all the way to Malayo-Polynesian and Formosan languages) and with the loss of the combined POc suffixes $*_{-} i, *_{-}$aki still attested in other Oceanic languages. The decay of such combinations has triggered the conflation of their respective functions and meanings onto the remaining prefixes, leaving the resulting semantic ambiguities to be clarified by additional suffixes, adjuncts, or adverbs (Section 2.6.5). Second, in the southern languages, the decay has extended to the prefixes themselves; polysemous transitive constructions with coreferential arguments have thus taken over the expression of the reciprocal, reflexive, and deagentive meanings (Section 2.3.2). Third, the languages of the Loyalty Islands show an intermediate situation (Section 2.2), since this network of functions and meanings is distributed over three different strategies: the reflexes of POc *paRi-, transitive constructions with coreferential arguments, and (renewed) reduplication. The M-prefixes do not usually combine with reduplication, but they tend to have some overlapping functions and meanings.

3.2.4. Competing strategies for middle functions: M-prefixes and constructions with coreferential arguments. Other Oceanic languages display competing strategies to encode middle notions.

In Toqabaqita (Lichtenberk 1991: 174-178, 181), though the prefix kwaiis not a reflex of POc *paRi-, it has similar functions. The middle constructions with kwai-...(-i) are depatientive and intransitivizing; they also express reciprocity as in kwai-kumu-i 'fight, exchange blows' ( $<$ kити 'punch') or collective/cooperative actions involving undifferentiated events or participants as in kwai-'adomi 'do together, cooperate in doing' ( $<$ 'adomi 'help'). The prefix $k w a i-$ generally refers to temporally non-distinct, simultaneous actions constituting one undifferentiated whole, to generic or habitual situations, to properties of the subject as in kwai-thatai 'be ready (to do something)' (< thatai 'make something ready', Lichtenberk 1991: 182), see also (54a, b). Transitive constructions with coreferential arguments constitute the competing strategy for reciprocal and self-directed meanings, but show possible ambiguity as in $(54 c)$. 
a. Wane 'e kwai-ilamata'i.

man 3sG kwai-hate

'This man is hateful.' (Lichtenberk 1991: 179)

b. Oomea 'eri 'e kwai-fa'a-ma'u-i.

enemy that 3sG kwai-CAUS-be.frightened-R

'The enemy is frightening.' ( $<f a$ ' $a-m a$ ' $u$ - $i$ 'frighten') (Lichtenberk 1991: 178)

c. Keero'a keko thathami keero'a.

3DU 3DU like 3DU

'They like each other.' or: 'They like themselves.' or: 'They like them.' (Lichtenberk 1991: 172)

Reciprocals may be disambiguated by the adjunct kwailiu 'back and forth, respectively, all over the place', an innovated compound of the prefix kwai- and the verb liu '(take) a walk, walk about' (Lichtenberk 1991: 178). In contrast with reciprocals marked by kwai-...(-i), these constructions with coreferential arguments often refer to temporally distinct actions, done in turns, sequentially.
a. Roo wela kera fa'a-ma'u keero'a kwailiu. two child 3DU frighten 3DU REC 'The two children frighten each other.' (Lichtenberk 1991: 178)
b. Kera 'adomi keero'a kwailiu.
3DU help 3DU REC
'They helped each other.' (Lichtenberk 1991: 172)

Mwotlap (Vanuatu; François 2001: 250-251) offers another example of the competing functions of the prefix and the constructions with coreferential arguments for reciprocals and reflexives. The polysemous prefix $v \bar{e} y$ - which carries reciprocal as well as competitive and intensive meanings (but no collective meaning) is now semi-productive. Thus reciprocals are increasingly encoded by coreferential arguments (56a); again, possible ambiguities are removed by various adjuncts, as in New Caledonian languages. Thus, the reversive-locative marker lok 'back', combined with the restrictive nominal mahge 'alone, only', expresses self-directed processes (56c), for lok by itself does not remove all ambiguities, as shown by (56b) (compare with hada 'alone' in Nêlêmwa; Section 2.6.5.3).

a. Kēy mu-wuh mat kēy.

3PL PFT-hit die 3PL

'They killed each other.' or: 'They killed themselves.' or: 'They killed them.' (François 2001: 250) 
b. Kēy mu-wuh mat lok kēy. 3PL PFT-hit die REV 3PL

'They killed themselves.' or: 'They killed them again.' (also marginally reciprocal) (François 2001: 251)

c. Kōyō vēhge lok kōyō mahge-yō.

3DU AO.ask REV 3DU alone-POss.3DU

'They are wondering, lit. they are asking themselves' (François personal communication)

As in Austronesian languages, but in contrast with New Caledonian languages, reduplication in Mwotlap is very productive (François 2001: 143-150): it expresses plurality, intensity, diminutive, augmentative, dispersive meanings, iterative, habitual, frequentative, non-completed aspects and it derives intransitive verbs and deverbal nouns. The meanings and functions of the decaying M-prefixes in Mwotlap are taken over either by constructions with coreferential arguments (for reciprocal and self-directed actions) or by reduplication (for other meanings). By contrast, in northern New Caledonian languages, most of these functions and meanings are carried by the M-prefixes and/or coreferential arguments.

These data show how the loss of a productive morphological marker triggers the conflation of several of its former functions and meanings onto some other available morpheme(s) or construction(s), and the use of adjuncts to compensate for the resulting ambiguity.

3.2.5. Other strategies: Combined reduplication and coreferential arguments; polysemous reduplication. Some Oceanic languages display yet other strategies. In Bislama (Vanuatu), reciprocals are expressed by combining reduplication and transitive constructions with coreferential arguments: tufala kiskis-im tufala [3DU kiss-RED-TR 3DU] 'they kissed each other'; iumitu laeklaek-im iumitu [1DU.INCL like-RED-TR 1DU.INCL] 'we like each other' (Charpentier personal communication).

In Port-Sandwich (Vanuatu; Charpentier 1979: 138-148), reduplication and repetition express plural relationship as well as the whole middle domain, including reciprocal, iterative, intensive, distributive, continuous/non-completed actions, and reference to states or properties. Here are some examples of the reciprocal meaning expressed by repeating the verb and its clitic subject pronoun: u-tux u-tux [3DU-fight 3DU-fight] 'they (two) fight each other with fists' (Charpentier 1979: 147); u-samb u-samb [3DU-be.bad 3DU-be.bad] 'they (two) are mutual enemies' (Charpentier 1979: 148). 
3.3. The evolution of middle constructions in Austronesian languages: Decay, recombination, complexification, and diversification

Austronesian languages thus provide another illustration of a commonly attested fact, the diversification of functions and meanings of middle markers during the course of their evolution, sometimes away from their original source (Kemmer 1993: 240).

Here is a short summary of the comparative data analysed so far:

(i) Formosan languages display different sets of reciprocal prefixes for active or non-active predicates and finite or nonfinite verb forms (Sections 1.2 and 3.1.1); when combined with root reduplication, they mark a plurality of reciprocal relationship (Section 3.1.1).

(ii) Western Malayo-Polynesian languages display more polysemous prefixes, expressing reciprocal, reflexive actions, continuous/non-completed actions, intensity; they often combine with reduplication to express plural relationship, iterative, intensive, or attenuative meanings (Section 3.1.2).

(iii) In Oceanic languages, the reflexes of POc *paRi- evidence variable degrees of productivity and polysemy with sometimes opposite evolutionary patterns (Section 3.2 ), either as highly polysemous and productive morphemes or as decaying morphemes gradually replaced by other types of constructions. Yet their core meanings and functions remain reciprocity, collective, and lower transitivity.

In Oceanic languages, three main strategies have been identified as expressing the middle domain: the reflexes or POc *paRi-, reduplication, and transitive constructions with coreferential arguments (mostly for reflexives and reciprocals). They may combine (Section 3.2). The decay of some elements triggers some type of systemic reorganization and recombination, sometimes inducing the semantic and functional diversification and complexification of one specific strategy over the others. This, in turn, triggers ambiguity and necessitates lexical disambiguizers (generally adjuncts, Sections 2.6.5 and 3.2.4) or new morphological combinations (Section 2.2.1).

Oceanic languages show various paths of evolution which can be summarized as follows:

(i) Combination: preservation of the original pattern which combines the reflexes of POc *paRi- with the suffixes $*_{-} i, *_{-a k i}$ or with reduplication, to express reciprocals, plurality of relation, and various other meanings (iterative, intensive, distributive), as in Mekeo, Fijian, Samoan (Table 1, Section 3.2.1).

(ii) Dissociation/split: complementary distribution of the reflexes of POc *paRi- (for reciprocals) and of reduplication (for other meanings) with distinct functions and meanings, as in Manam, Tolai, Futunan (Section 
3.2.2); Fijian has both patterns of combination and complementary distribution with distinct functions and meanings (Section 3.2.1).

(iii) Decay, recombination, complexification, and diversification:

(a) decay of reduplication correlated with the development of polysemous reflexes of POc *paRi- with a complexified range of functions and meanings (as in northern New Caledonian languages; Section 3.2.3), and with a tendency for the prefix to specialize as a depatientive middle marker when used alone;

(b) decay of the reflexes of POc *paRi- and of reduplication, which correlates with the complexified range of functions and meanings of the transitive constructions with coreferential arguments (in the southern languages of New Caledonia; Section 2.3.2); the complexification of this specific construction can be predicted to extend from reflexives to reciprocals, and then to other middle notions (as in Xârâcùù); thus, in Nêlêmwa (north), where reflexives and reciprocals have different constructions, reflexives are marked by coreferential subject and object arguments, whereas reciprocal actions are marked by the prefix $p e-\ldots-i$ or by $p e$ combined with coreferential arguments (Section 2.5);

(c) decay of the reflexes of POc *paRi-, correlated with productive and polysemous reduplication (Port-Sandwich; Section 3.2.5).

(iv) Competing and overlapping strategies: synchronically competing strategies such as those found in Xârâcùù (Sections 2.3.1 and 2.3.2), Toqabaqita, and Mwotlap (Section 3.2.4), in which either the M-prefixes or coreferential arguments of transitive constructions have partly overlapping functions and meanings, signal some reorganization of the system, triggered in these particular cases by an ongoing decay of the reflexes of POc *paRi-.

\section{Austronesian in crosslinguistic perspective}

Kemmer (1993: 100) states that there are limits to the extension of polysemy and that the three-way polysemy between reflexive, collective, and reciprocal is infrequent. This infrequent type appears in Oceanic languages, especially in New Caledonian languages which provide not only instances of that threeway polysemy of the middle prefixes (so do some Australian languages ${ }^{35}$ ), but also a much wider ranging semantic extension including various aspectual or "adverbial" meanings (Section 2.6.4). This article has attempted to retrace the pathways of the functional or semantic extension of these prefixes in New

35. Such as languages of the Nyulnyulan family (McGregor 2000: 114), Bininj Gun-wok, or Djapu (Evans 2003) which also have a single form for reflexive, collective, and reciprocals, though with some syntactic differences. In Bininj Gun-wok (Evans 2003), the suffix is -rr for all these functions. 
Caledonian languages, from their core to their peripheral uses, some of which (solipsism, intensive) may be sufficiently distant from the core that the path of semantic extension may be difficult to retrace, thus giving rise in the long term to homophonous morphemes.

The second issue addressed is the type of evolution at hand. Kemmer (1993: 223) states that, crosslinguistically, middle markers mostly originate from reflexives, and that the evolution from reciprocals to middle is a crosslinguistic rarity.

Again, Austronesian languages provide examples of this rarity. ${ }^{36}$ As already pointed out, there is no reconstructed Proto-Austronesian or Proto-Oceanic reflexive morpheme. Rather, as evidenced by their reflexes in Formosan languages (Zeitoun 2002; see Sections 1.2 and 3.1.1), these prefixes were originally reciprocal prefixes, which underwent some functional or semantic extension in Proto-Malayo-Polynesian (PMP *paR-; Reid 1987, Zobel 2002, Ross in press, Blust forthcoming; see Section 1.2), as shown by the data from Tagalog, Malay, or Indonesian (Section 3.1.2). Thus, Tagalog mag- and Malay and Indonesian ber- are actor focus, intransitivizing morphemes expressing a wide range of meanings, reciprocal, collective actions, plural relationship, reflexive, durative actions, states, and properties (Section 3.1.2).

These prefixes often combine with reduplication. In Formosan languages (Zeitoun 2002), the reciprocal affixes combine with root reduplication to indicate plural reciprocal participants (Section 3.1.1). In Malayo-Polynesian languages, the M-prefixes also combine with reduplication to indicate a plurality of actions or participants, as well as intensive, aimless, non-completed actions (Section 3.1.2). But, Malayo-Polynesian languages have innovated since the prefixes alone also convey the collective and plural meanings (see Tagalog mag-, Section 1.2, and Malay ber-, Section 3.1.2). Such semantic innovation can be seen as naturally stemming from the notion of reciprocal actions. This feature was inherited by Oceanic languages.

Besides, these prefixes are low transitivity markers: they associate with nonactive verbs in Formosan languages and they are intransitive actor focus, middle prefixes in Malayo-Polynesian languages (Section 1.2). From reciprocity and low transitivity, their functions and semantics then extended and diversified further into the middle domain to include reflexivity or situations indicating the lack of initiator or of patient, the lack of aspectual endpoint (Section 2.6.4) with reference to unbounded, non-completed, or durative actions, the reference to generic and stative properties, etc.

36. Australian languages provide other examples of an evolution from reciprocal to reflexive, since the old reciprocal suffix *-nyji has extended to reflexive use independently in two language families, Nyulnyulan and Gunwinyguan (Alpher et al. 2003). 
Many Oceanic languages (Section 2.7) have inherited these functions and meanings, though with some variations and some loss. Northern New Caledonian languages have pushed this diversification one step further and innovated by conflating onto the prefixes a number of the meanings (especially distributive and dispersive) usually devolved to the combined POc affixes * paRi-...-aki or to combined reduplication in other Oceanic languages (Section 2.6.4.2). To demonstrate this, it was essential to compare the New Caledonian data with other Austronesian languages to distinguish inheritance from the innovations specific to the northern New Caledonian languages.

Received: 15 February 2002

LACITO-CNRS Revised: 25 November 2004

Correspondence address: LACITO-CNRS, Centre André-Georges Haudricourt, 7 Rue Guy Môquet (Bât. D), 94801 Villejuif Cedex, France; e-mail: ibril@vjf.cnrs.fr

Acknowledgements: I would like to thank Jean-Claude Rivierre who, at an earlier stage of this research, suggested to me to investigate the possible correlation between some aspects of the polysemy of these prefixes and the decay of reduplication in northern New Caledonian languages. I would also like to thank the anonymous reviewers of Linguistic Typology, Nicholas Evans, and Frans Plank for their many insightful comments, questions, and suggestions on earlier versions of this paper, which greatly contributed to its improvement.

Abbreviations: AGT agent marker; ACT actualizer; ANAPH anaphoric; AO aorist; ART article; ASS assertive; ASSOC associative; CAUS causative; CLASS classifier; COLL.OBJ collective object; COMIT comitative; CONN connector; CONT continuous; DEICT deictic marker; DEPEND dependency marker; DIR directional; DU dual; DUR durative; EXCL exclusive; EXPL explicative; FUT future; IMPN impersonal pronoun; INCL inclusive; lit. literal translation; LOC localizer; LOC.PRED locative predicate; NEG negation; NEG.PRED negative predicate; NON-COMPL non-completed; PERF perfective; PFT perfect; PL plural; POSS possessive; PREF prefix; PREP preposition; PROG progressive; -R reciprocal suffix; REC reciprocal; REV reversive; SG singular; SM subject marker; TOP topic marker; TR transitive marker.

Abbreviations of proto-languages: PAn Proto-Austronesian; PEF Proto-Extra-Formosan; PMP Proto-Malayo-Polynesian; POc Proto-Oceanic. 
Appendix 1. Family grouping of the Austronesian languages cited; groups not represented in this study are omitted

AUSTRONESIAN

FORMOSAN LANGUAGES (several subgroups): Rukai, Pazeh, Paiwan,

Saisiyat, Puyuma

MALAYO-POLYNESIAN/EXTRA-FORMOSAN (see Footnote 4)

WESTERN MALAYO-POLYNESIAN: Tagalog, Malay

CENTRAL-EASTERN MALAYO-POLYNESIAN: Indonesian

OCEANIC

WESTERN OCEANIC

North New Guinea: Manam

West Central Papuan, Papuan Tip: Mekeo

Meso Melanesian: Tolai

EASTERN OCEANIC: Toqabaqita

REMOTE OCEANIC

North Central Vanuatu: Mwotlap, Port-Sandwich

New Caledonia

CENTRAL PACIFIC: Fijian

POLYNESIAN: Tongan, Samoan, Futunan 


\section{Isabelle Bril}

Appendix 2. Reflexes of Proto-Oceanic *paRi- in New Caledonian languages

\begin{tabular}{|c|c|c|c|}
\hline Alignment system & Location & Language & Morpheme \\
\hline Ergative & Far North & $\begin{array}{l}\text { Nêlêmwa } \\
\text { Nixumwak } \\
\text { Nyêlayu }\end{array}$ & $\begin{array}{l}p e-\ldots(-i) \\
p e-\ldots(-i) \\
p e-\ldots\end{array}$ \\
\hline Split ergative & North & $\begin{array}{l}\text { Yuanga } \\
\text { Caac } \\
\text { Jawe } \\
\text { Nemi } \\
\text { Fwâi } \\
\text { Pije } \\
\text { Pwapwâ } \\
\text { Pwaamei }\end{array}$ & $\begin{array}{l}\text { pe- } \\
\text { pe- } \sim \text { phe- } \\
\text { pe- } \\
\text { pe- } \\
\text { pe- } \\
\text { pe-, ve- } \\
\text { pe- } \\
\text { pe- }\end{array}$ \\
\hline Accusative & Centre-North & $\begin{array}{l}\text { Cèmuhî } \\
\text { Paicî } \\
\text { Hmwaveke } \\
\text { Hmwaeke } \\
\text { Haeke } \\
\text { Bwatoo }\end{array}$ & $\begin{array}{l}\text { pi- } \\
p i- \\
v e- \\
v e- \\
v e- \\
v e-\end{array}$ \\
\hline Accusative & $\begin{array}{l}\text { Centre-South } \\
\text { and South }\end{array}$ & $\begin{array}{l}\text { Ajië } \\
\text { Xârâcùù }\end{array}$ & $\begin{array}{l}v i- \\
\grave{u}-\end{array}$ \\
\hline Accusative & Far South & $\begin{array}{l}\text { Numèè } \\
\text { Kwenyi }\end{array}$ & $\begin{array}{l}v i- \\
v i-\end{array}$ \\
\hline $\begin{array}{l}\text { Ergative or } \\
\text { accusative }\end{array}$ & Loyalty Islands & $\begin{array}{l}\text { Iaai } \\
\text { Drehu } \\
\text { Nengone }\end{array}$ & $\begin{array}{l}\ddot{u}-\sim i \text {-...köu } \\
i \text {-...keu; } i \text { - (restricted recip.) } \\
e-\sim i . . j e u\end{array}$ \\
\hline
\end{tabular}




\section{Appendix 3. Sources for the New Caledonian languages}

\begin{tabular}{lll}
\hline Far North & Nêlêmwa, Nixumwak & Bril 2000, 2002 \\
North & Ozanne-Rivierre 1998 \\
& Caac & Hollyman 1971 \\
& Jawe & Haudricourt \& Ozanne-Rivierre 1982 \\
& Nemi & Ozanne-Rivierre 1979 \\
& Pwapwâ & Haudricourt no date \\
& Pwaamei & Haudricourt no date \\
& Cèmuhî & Rivierre 1980 \\
& Bwatoo & Ehrhart \& Rivierre forthcoming \\
Ajië & La Fontinelle 1976 \\
& Tîrî & Osumi 1995 \\
Xârâcùù & Moyse-Faurie 1995 \\
& Iaai & Ozanne-Rivierre 1976, 1984 \\
& East Uvean & Ozanne-Rivierre 1986 \\
Loyalty Islands & Lenormand no date, 1999; Moyse-Faurie \\
& & 1983; Sam 1995 \\
& Nengone & Dubois no date, Tryon 1967, Cawa 2000 \\
\hline
\end{tabular}

\section{References}

Adelaar, K. Alexander (1984). Some Proto-Malayic affixes. Bijdragen tot de Taal-, Land-en Volkenkunde 140: 402-421.

- (1992). Proto-Malayic: The Reconstruction of its Phonology and Parts of its Lexicon and Morphology. (Pacific Linguistics, C-119.) Canberra: Australian National University.

- (2000). Siraya reduplication. Oceanic Linguistics 39: 33-52.

Alpher, Barry, Nicholas Evans, \& Mark Harvey (2003). Proto-Gunwinyguan verb suffixes. In Nicholas Evans (ed.), The Non-Pama-Nyungan Languages of Northern Australia: Comparative Studies of the Continent's most Linguistically Complex Region (Pacific Linguistics, 552), 305-352. Canberra: Australian National University.

Aramiou, Sylvain et al. (2001). Dictionnaire ajië-français. (Collection Bwêwêyê.) Nouméa: Fédération de l'Enseignement Libre Protestant.

Bender, Byron W. (1971). Micronesian languages. In Thomas A. Sebeok (ed.), Current Trends in Linguistics, Volume 8: Linguistics in Oceania, 426-465. The Hague: Mouton.

Benveniste, Emile (1966). Problèmes de linguistique générale. Paris: Gallimard.

Blust, Robert (1988). Malay historical linguistics: A progress report. In Thani Ahmad Mohd \& Zaini Mohamed Zain (eds.), Rekonstruksi Dan Cabang-cabang Bahasa Melayu Induk, 1-34. Kuala Lumpur: Dewan Bahasa Dan Pustaka, Kementerian Pendidikan Malaysia.

- (1998). Ca-reduplication and Proto-Austronesian grammar. Oceanic Linguistics 37: 29-64.

- (forthcoming). Austronesian Comparative Dictionary.

Bril, Isabelle (2000). Dictionnaire nêlêmwa-nixumwak (Nouvelle-Calédonie). (Collection Langues et Cultures du Pacifique, 14.) Paris: Peeters.

- (2002). Le nêlêmwa (Nouvelle-Calédonie): Analyse syntaxique et sémantique. (Collection Langues et Cultures du Pacifique, 16.) Paris: Peeters.

- (forthcoming). Polysemy of the reciprocal marker in Nêlêmwa. In Nedjalkov \& Guentchéva (eds.) forthcoming.

Capell, Arthur (1973). A New Fijian Dictionary. Suva, Fiji: Government Printer. 
Cawa, Davel (2000). Un exemple de morphosyntaxe en nengone (Nouvelle-Calédonie): Les variations morphologiques et la transitivité. In Bill Palmer \& Paul Geraghty (eds.), SICOL: Proceedings of the Second International Conference on Oceanic Linguistics, Volume 2: Historical and Descriptive Studies (Pacific Linguistics, 505), 285-293. Canberra: Australian National University.

Charpentier, Jean-Michel (1979). La langue de Port-Sandwich (Nouvelles-Hébrides): Introduction phonologique et grammaire. (Langues et Civilisations à Tradition Orale, 34.) Paris: SELAF.

Churchward, C. Maxwell (1941). A New Fijian Grammar. Sydney: Australasian Medical Publishing Company.

- (1953). Tongan Grammar. London: Oxford University Press.

Croft, William (1991). Syntactic Categories and Grammatical Relations. Chicago: University of Chicago Press.

Dixon, R. M. W. (1988). A Grammar of Boumaa Fijian. Chicago: University of Chicago Press.

Dubois, M. J. (no date). Dictionnaire nengone-français. Unpublished manuscript.

Ehrhart, Sabine \& Jean-Claude Rivierre (forthcoming). Dictionnaire bwatoo-français (NouvelleCalédonie).

Evans, Nicholas (2003). Bininj Gun-wok: A Pan-dialectal Grammar of Mayali, Kunwinjku and Kune. 2 volumes. (Pacific Linguistics, 541.) Canberra: Australian National University.

Frajzyngier, Zygmunt \& Traci S. Curl (eds.) (2000). Reciprocals: Forms and Functions. Amsterdam: Benjamins.

François, Alexandre (2001). Contraintes de structures et liberté dans l'organisation du discours: Une description du mwotlap, langue océanienne du Vanuatu. Doctoral dissertation, Université de Paris IV (Paris-Sorbonne).

Hagège, Claude \& André-Georges Haudricourt (1978). La phonologie panchronique. Paris: Presses Universitaires de France.

Harrison, Sheldon P. (1973). Reduplication in Micronesian. Oceanic Linguistics 12: 407-454.

Hassan, Abdullah (1974). The Morphology of Malay. Kuala Lumpur: Dewan Bahasa Dan Pustaka.

Haudricourt, André-Georges (no date). Notes manuscrites sur le Pwaamei, Pwapwâ. Unpublished manuscript.

Haudricourt, André-Georges \& Françoise Ozanne-Rivierre (1982). Dictionnaire thématique des langues de la région de Hienghène (Nouvelle-Calédonie). (LACITO Documents: AsieAustronésie, 4.) Paris: SELAF.

Himmelmann, Nikolaus P. (2004). Tagalog. In Geert Booij, Christian Lehmann, Joachim Mugdan, \& Stavros Skopeteas (eds.), Morphology: A Handbook on Inflection and Word Formation, Volume 2. 1473-1490. Berlin: de Gruyter.

- (forthcoming a). Tagalog. In K. Alexander Adelaar \& Nikolaus P. Himmelmann (eds.): The Austronesian Languages of Asia and Madagascar: Typological Characteristics. London: Routledge/Curzon.

- (forthcoming b). Lexical categories and voice in Tagalog. In Peter Austin \& Simon Musgrave (eds.), Grammatical Relations and Voice in Austronesian. Stanford: CSLI.

Hollyman, Jim K. (1971). Dictionnaire caaàc-français. Unpublished manuscript.

Jones, Alan A. (1998). Towards a Lexicogrammar of Mekeo (an Austronesian Language of Western Central Papua). (Pacific Linguistics, C-138.) Canberra: Australian National University.

Kemmer, Suzanne E. (1993). The Middle Voice. Amsterdam: Benjamins.

La Fontinelle, Jacqueline de (1976). La langue de Houaïlou (Nouvelle-Calédonie). (Langues et Civilisations à Tradition Orale, 17.) Paris: SELAF.

Leenhardt, Maurice (1932). Documents néo-calédoniens. (Travaux et Mémoires de l'Institut d'Ethnologie, 9.) Paris: Institut d'Ethnologie, Université de Paris.

- (1935). Vocabulaire et grammaire de la langue houaïlou. (Travaux et Mémoires de l'Institut d'Ethnologie, 10.) Paris: Institut d'Ethnologie, Université de Paris.

Lenormand, Maurice (no date). Dictionnaire lifou-français. Unpublished manuscript. 
- (1999). Dictionnaire de la langue de Lifou, Iles Loyauté (Nouvelle-Calédonie). Nouméa, New Caledonia: Le Rocher-à-la-voile.

Lichtenberk, Frantisek (1983). A Grammar of Manam. (Oceanic Linguistics Special Publications, 18.) Honolulu: University of Hawaii Press.

- (1985). Multiple uses of reciprocal constructions. Australian Journal of Linguistics 5: 19-41.

- (1991). Reciprocals and depatientives in Toqabaqita. In Robert Blust (ed.), Currents in Pacific Linguistics: Papers on Austronesian Languages and Ethnolinguistics in Honour of G. W. Grace (Pacific Linguistics, C-117), 171-183. Canberra: Australian National University.

- (2000). Reciprocals without reflexives. In Frajzyngier \& Curl (eds.) 2000, 30-62.

Lombard, Denys (1977). Introduction à l'indonésien. (Cahier d'Archipel, 1.) Paris: S.E.C.M.I.

Lopez, Cecilio (1940). A Manual of the Philippine National Language. Manila: Bureau of Printing.

McGregor, William (2000). Reflexive and reciprocal in Nyulnyulan languages. In Frajzyngier \& Curl (eds.) 2000, 85-122.

Milner, G. B. (1966). Samoan Dictionary. Oxford: Oxford University Press.

- (1972). Fijian Grammar. Fiji: Government Press Suva.

Mosel, Ulrike (1984). Tolai Syntax and its Historical Development. (Pacific Linguistics, B-92.) Canberra: Australian National University.

Mosel, Ulrike \& Even Hovdhaugen (1992). Samoan Reference Grammar. Oslo: Scandinavian University Press.

Moyse-Faurie, Claire (1983). Le drehu, langue de Lifou (Iles Loyautés). (Langues et Cultures du Pacifique, 3.) Paris: SELAF.

- (1995). Le xârâcùù, langue de Thio-Canala (Nouvelle-Calédonie). (Langues et Cultures du Pacifique, 10.) Paris: SELAF.

- (forthcoming a). Reciprocal constructions in Futunan. In Nedjalkov \& Guentchéva (eds.) forthcoming.

- (forthcoming b). Reflexive and middle in some Polynesian and New Caledonian languages. In Ahmed Brahim \& Zlatka Guentchéva (eds.), Reflexive and Middle: Typological Approaches. Tunis.

Nedjalkov, Vladimir P. \& Zlatka Guentchéva (eds.) (forthcoming). Typology of Reciprocal Categories and Constructions.

Osumi, Midori (1995). Tinrin Grammar (New Caledonia). (Oceanic Linguistics Special Publication, 25.) Honolulu: University of Hawaii Press.

Ozanne-Rivierre, Françoise (1976). Le iaai, langue d'Ouvéa (Nouvelle-Calédonie). (Langues et Civilisations à Tradition Orale, 20.) Paris: SELAF.

- (1984). Dictionnaire iaai-français (Ouvéa, Nouvelle-Calédonie). (Langues et Cultures du Pacifique, 6.) Paris: SELAF.

- (1986). Redoublement expressif et dédoublement des séries consonantiques dans les langues des Îles Loyauté (Nouvelle-Calédonie). Te Reo 29: 25-53.

- (1979). Textes nemi (Nouvelle-Calédonie). (Langues et Civilisations à Tradition Orale, 31.) Paris: SELAF.

- (1998). Le nyelâyu de Balade (Nouvelle-Calédonie). (Langues et Cultures du Pacifique, 12.) Paris: Peeters.

Pawley, Andrew (1973). Some problems in Proto-Oceanic grammar. Oceanic Linguistics 12: 103188.

Pawley, Andrew \& Lawrence A. Reid (1979). The evolution of transitive constructions in Austronesian. In Paz B. Naylor (ed.), Austronesian Studies: Papers from the Second Eastern Conference on Austronesian Languages (Michigan Papers on South and Southeast Asia, 15), 103-130. Ann Arbor: Center for South and Southeast Asian Studies, University of Michigan.

Pittman, Richard (1966). Tagalog -um- and mag-: An interim report. In Papers in Philippine Linguistics 1, (Linguistic Circle of Canberra Publications, A 8), 9-20. Canberra: Australian National University. 
Reid, Lawrence A. (1987). The early switch hypothesis: Linguistic evidence for contact between Negritos and Austronesians. Man and Culture in Oceania 3 (Special Issue): 41-59.

Reid, Lawrence A. \& Hsiu-chuan Liao (2004). A brief syntactic typology of Philippine languages. Language and Linguistics 5: 433-490.

Rivierre, Jean-Claude (1980). La langue de Touho: Phonologie et grammaire du cèmuhî. (Langues et Civilisations à Tradition Orale, 30.) Paris: SELAF.

- (1993). Tonogenesis in New Caledonia. In Jerold A. Edmonson \& Kenneth J. Gregerson (eds.), Tonality in Austronesian Languages (Oceanic Linguistics Special Publication, 24), 155-173. Honolulu: University of Hawaii Press.

- (1994). Dictionnaire cemuhî-français (Nouvelle-Calédonie). (Langues et Cultures du Pacifique, 9.) Paris: Peeters.

Ross, Malcolm D. (2002). The history and transitivity of Western Austronesian voice and voicemarking. In Wouk \& Ross (eds.) 2002, 17-62.

- (forthcoming). Notes on the prehistory and internal subgrouping of Malayic. In John Bowden \& Nikolaus Himmelmann (eds.), Papers in Austronesian Subgrouping and Dialectology (Pacific Linguistics). Canberra: Australian National University.

Rubino, Carl G. U. (2000). Ilocano Dictionary and Grammar. Honolulu: University of Hawai'i Press.

Sam, Drilë Léonard (1995). Dictionnaire drehu-français (Lifou, Nouvelle-Calédonie). Nouméa: Centre territorial de recherche et de documentation pédagogique de Nouvelle-Calédonie.

Schachter, Paul (1987). Tagalog. In Bernard Comrie (ed.), The World's Major Languages, 936958. New York: Oxford University Press.

Schachter, Paul \& Fe T. Otanes (1972). Tagalog Reference Grammar. Berkeley: University of California Press.

Schütz, Albert J. (1985). The Fijian Language. Honolulu: University of Hawaii Press.

Tryon, Darrell (1967). Nengone Grammar. (Pacific Linguistics, B-6.) Canberra: Australian National University.

Wolff, John U. (1973). Verbal inflection in Proto-Austronesian. In Andrew B. Gonzalez (ed.), Parangal kay Cecilio Lopez: Essays in Honor of Cecilio Lopez on his Seventy-fifth Birthday, 71-91. Quezon City: Linguistic Society of the Philippines.

- (1996). The development of the passive verb with pronominal prefix in Western Austronesian languages. In Bernd Nothofer (ed.), Reconstruction, Classification, Description: Festschrift in Honor of Isidore Dyen, 15-40. Hamburg: Abera.

Wouk, Fay \& Malcolm Ross (eds.) (2002). The History and Typology of Western Austronesian Voice Systems. (Pacific Linguistics, 518.) Canberra: Australian National University.

Zeitoun, Elisabeth (2002). Reciprocals in the Formosan languages: A preliminary study. Paper presented at the Ninth International Conference on Austronesian Languages (9-ICAL), Canberra, 8-11 January 2002.

Zobel, Erik (2002). The position of Chamorro and Palauan in the Austronesian family tree: Evidence from verb morphosyntax. In Wouk \& Ross (eds.) 2002, 405-434.

Zorc, David (1977). The Bisayan Dialects of the Philippines: Subgrouping and Reconstruction. (Pacific Linguistics, C-44.) Canberra: Australian National University. 